OPEN ACCESS

Edited by:

Pierre Amato,

UMR6296 Institut de Chimie de Clermont-Ferrand (ICCF), France

Reviewed by:

Anne D. Jungblut,

Natural History Museum,

United Kingdom

Trista J. Vick-Majors,

The University of Montana,

United States

${ }^{*}$ Correspondence:

Birgit Sattler

Birgit.Sattler@uibk.ac.at

Specialty section:

This article was submitted to

Extreme Microbiology,

a section of the journal

Frontiers in Microbiology

Received: 16 August 2018

Accepted: 24 April 2019

Published: 10 May 2019

Citation:

Weisleitner K, Perras A,

Moissl-Eichinger C, Andersen DT and Sattler B (2019) Source Environments of the Microbiome in Perennially

Ice-Covered Lake Untersee,

Antarctica. Front. Microbiol. 10:1019.

doi: 10.3389/fmicb.2019.01019

\section{Source Environments of the Microbiome in Perennially Ice-Covered Lake Untersee, Antarctica}

\author{
Klemens Weisleitner ${ }^{1,2}$, Alexandra Perras ${ }^{3}$, Christine Moissl-Eichinger ${ }^{4,5}$, \\ Dale T. Andersen ${ }^{6}$ and Birgit Sattler ${ }^{1,2 *}$
}

1 Institute of Ecology, University of Innsbruck, Innsbruck, Austria, ${ }^{2}$ Austrian Polar Research Institute, Vienna, Austria, ${ }^{3}$ Center for Medical Research (ZMF), Medical University of Graz, Graz, Austria, ${ }^{4}$ Department of Internal Medicine, Joint Facilities, Medical University of Graz, Graz, Austria, ${ }^{5}$ BioTechMed-Graz, Graz, Austria, ${ }^{6}$ SETI Institute, Mountain View, CA, United States

Ultra-oligotrophic Lake Untersee is among the largest and deepest surface lakes of Central Queen Maud Land in East Antarctica. It is dammed at its north end by the Anuchin Glacier and the ice-cover dynamics are controlled by sublimation - not melt as the dominating ablation process and therefore surface melt during austral summer does not provide significant amounts of water for recharge compared to subsurface melt of the Anuchin Glacier. Several studies have already described the structure and function of the microbial communities within the water column and benthic environments of Lake Untersee, however, thus far there have been no studies that examine the linkages between the lake ecosystem with that of the surrounding soils or the Anuchin Glacier. The glacier may also play an important role as a major contributor of nutrients and biota into the lake ecosystem. Based on microbial 16S rRNA amplicon sequencing, we showed that the dominant bacterial signatures in Lake Untersee, the Anuchin Glacier and its surrounding soils were affiliated with Actinobacteria, Bacteroidetes, Cyanobacteria, Firmicutes, and Proteobacteria. Aerosol and local soil depositions on the glacier surface resulted in distinct microbial communities developing in glacier ice and cryoconite holes. Based on a source tracking algorithm, we found that cryoconite microbial assemblages were a potential source of organisms, explaining up to $36 \%$ of benthic microbial mat communities in the lake. However, the major biotic sources for the lake ecosystem are still unknown, illustrating the possible importance of englacial and subglacial zones. The Anuchin Glacier may be considered as a vector in a biological sense for the bacterial colonization of the perennially ice-covered Lake Untersee. However, despite a thick perennial ice cover, observed "lift-off" microbial mats escaping the lake make a bidirectional transfer of biota plausible. Hence, there is an exchange of biota between Lake Untersee and connective habitats possible despite the apparent sealing by a perennial ice cover and the absence of moat areas during austral summer.

Keywords: Lake Untersee, 16S rRNA, Antarctica, Anuchin Glacier, cryoconite holes, transfer of biota, source tracking 


\section{INTRODUCTION}

The largest ice sheet on Earth covers more than $99.8 \%$ of continental Antarctica (Burton-Johnson et al., 2016). Here, the combination of strong winds, low temperatures, high radiation and low water availability are considered to be adverse to life (Boyd et al., 2013). However, there exist a range of habitats with distinct environmental conditions that host microbial dominated communities with active metabolism (Obbels et al., 2016).

The most prominent habitat on glacier surfaces is cryoconite holes that cover 1 to $10 \%$ of glacial ablation zones (Anesio and Laybourn-Parry, 2012). They form when dark organic and inorganic debris from local and distant sources attach to the ice surface and consequently decrease the albedo locally (Franzetti et al., 2017). Subsequently, debris melts into the ice, creating basins with sediments in the bottom and a liquid phase on top (Wharton et al., 1985; Takeuchi et al., 2001). Deposited biota that survives local conditions in these mini lakes proliferate while other organisms perish due to stress and competition (Anesio and Laybourn-Parry, 2012). In contrast to cryoconite holes in other regions, the majority of those in Antarctica are continuously ice-covered (Fountain et al., 2004; Cook et al., 2016) and solar-induced subsurface melt provides liquid water only for a mere fraction of the year. Further, they are disconnected from the atmosphere for most of the time, leading to unique environmental conditions such as extremely limited light intensities due to the ice lid (Bagshaw et al., 2016) or unusual hydrochemistry (Fountain et al., 2004). In addition to the habitats provided by cryoconite holes, liquid veins and thin layers of water coating dust grains support microbial life within the glacial ice matrix (Price, 2007). However, compared to cryoconite holes, microbial abundance (Boetius et al., 2015) and metabolic activity (Edwards et al., 2013a) in glacier ice are low.

Glaciers and ice sheets are hydrologically connected ecosystems that constantly receive abiotic and biotic matter and subsequently export material to adjacent downstream environments (Boetius et al., 2015). Therefore, glaciers should not be considered as stand-alone ecosystems but rather as an integral part of large-scale ecosystems. Consecutive habitats such as glaciers melting into lakes, influence their geochemical and microbial composition (Hotaling et al., 2017).

In many cases, Antarctic glaciers are the only obvious hydrological connection to adjacent perennially ice-covered lakes and hence the only source of nutrients and biota (Priscu et al., 1999). Besides subglacial and englacial microbial communities, also those from supraglacial zones may drain into an adjacent waterbody and therefore enable an indirect transfer of organic and inorganic matter from dust and aerosols into downstream aquatic ecosystems via glacial melt. Pre-adapted microorganisms may proliferate efficiently once being transferred to their sink environment. Such pre-adaptation processes may occur in actively metabolizing prokaryotes in the atmosphere (Amato et al., 2017), e.g., in super cooled cloud droplets (Sattler et al., 2001). In addition, aerial input of short and long-range transport are inoculation sources for cold habitats and near surface aerosol microbial communities differ from those within the soils (Bottos et al., 2014).
Here, the perennially ice-covered Lake Untersee is dammed by the Anuchin Glacier that gradually drains into the lake. Among others, studies at the Untersee Oasis included biogeochemical analyses of the water column (Wand et al., 1997, 2006; Haendel et al., 2011), microbial community analyses of benthic (Andersen et al., 2011; Koo et al., 2017b) and pelagic (Filippova et al., 2013; Fomenkov et al., 2017; Pikuta et al., 2017) habitats, and modeling of lake water circulation patterns (Steel et al., 2015). Further, long-term local climate conditions were recorded (Andersen et al., 2015). The research focus during the last decades was set on this lake since the perennial lake ice cover continuously disconnected the waterbody from the atmosphere for at least 500 years (Wand and Perlt, 1999).

As shown in the case of Lake Untersee, the majority of scientific investigations on specific polar environments have mostly been dealt with on a solitary basis, but not in a connective sense. Examples thereof are scarce (e.g., Diaz et al., 2018). However, to understand the linkages between cold habitats and their inoculation vectors (e.g., by melt processes and aeolian transport), a holistic ecosystem approach needs to be considered.

Here, we hypothesized that in the supraglacial zone (a) cryoconite hole microbial communities were dominated by microbial assemblages found in aerosols and adjacent soils and therefore differed from communities originating from bare glacier ice. Despite the presumably small volumetric fraction of cryoconite to the annual glacial melt water input, (b) cryoconite microbial communities can be mirrored in Lake Untersee environments. Biotic fluxes from the Anuchin Glacier to Lake Untersee were put in context by estimating the annual glacial melt volume and the volumetric fraction of cryoconite holes thereof.

\section{Study Site}

The Untersee Oasis is part of the Wohlthat Mountains, located nearby the Schirmacher Oasis in East Antarctica $\left(71.348^{\circ} \mathrm{S}\right.$, $13.458^{\circ} \mathrm{E}$, Figure 1). The area has been ice-free since the Last Glacial Maximum (Hiller et al., 1988), features the largest surface lake in the surrounding which formed during the Holocene (Schwab, 1998) and has no marine origin. The ultra-oligotrophic Lake Untersee located at $610 \mathrm{~m}$ above sea level (REMA dataset; Howat et al., 2018) has been continuously ice-covered for at least 500 years (Wand and Perlt, 1999) and is dammed at the northern tip by the Anuchin Glacier with a $\sim 0.68 \mathrm{~km}^{2}$ large ice wall (Steel et al., 2015) that provides the only known liquid water and nutrient source for the lake ecosystem. Water-loss only occurs through sublimation of the perennial lake ice cover (Hermichen et al., 1985). Ablation of $\sim 60 \mathrm{~cm} \mathrm{a}^{-1}$ ice thickness during the austral summer is compensated by refreezing of lake water at the bottom of the ice cover during the winter months (Wand and Perlt, 1999). The lake has a $169 \mathrm{~m}$ deep basin adjacent to the glacier. Here, the $\mathrm{pH}$ reaches values up to 12.1 (Wand et al., 2006). The water column is well mixed, oxygenated and pigmented microbial mats were found up to a depth of $100 \mathrm{~m}$. In shallower waters, modern large conical stromatolites and other benthic microbial mats were discovered (Andersen et al., 2011). These formations are unique to Lake Untersee. Further, a smaller anoxic sub-basin in the southern part of the lake is separated by sill and is physically and 


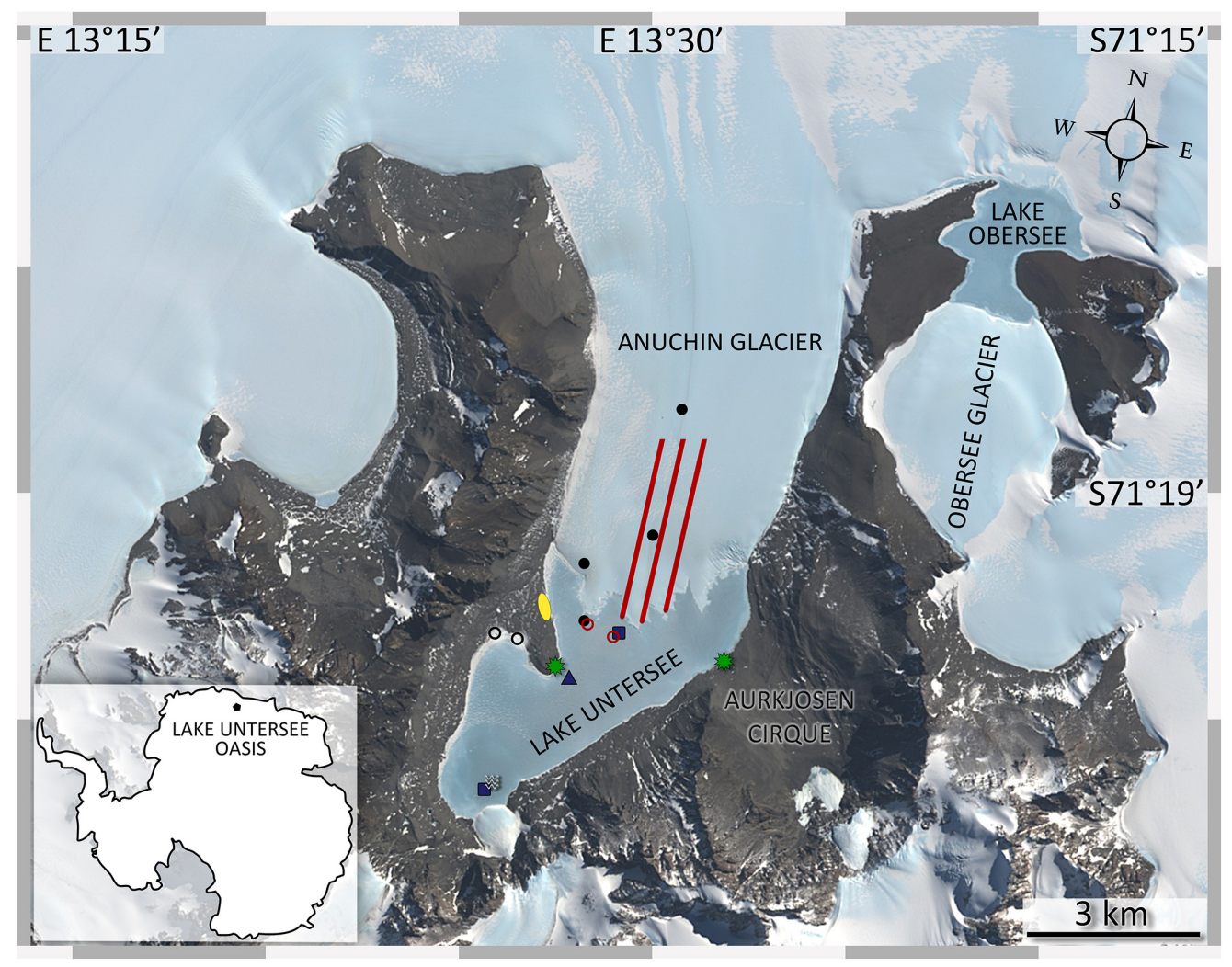

FIGURE 1 | Sampling sites at Lake Untersee Oasis. The image was captured by the Landsat 8 satellite (download via LIMA database from United States Geographical Survey) and color bands 2, 3, 4 were applied to the high-resolution band 8. Lake Untersee is dammed in the north by the Anuchin Glacier. Black dots (cryoconite holes), blue squares (lake sediments), blue triangle (benthic microbial mats), black circles (terrestrial samples), red lines (glacier ice transect, AT1-AT2-AT3 from left to right), red circles (white ice in lake ice cover and lake ice), and a white wave symbol (pelagic samples) indicate the sampling sites. Meteorological stations are indicated by green stars. The yellow ellipse marks the campsite. Overlapping symbols indicate that the sampling site for different sample types was identical.

chemically stratified from $50 \mathrm{~m}$ to the bottom $(100 \mathrm{~m})$. Here, high methane concentrations (>20 $\mathrm{mmol} \mathrm{l}^{-1}$ ) build up due to methanogenesis in surface sediments and the water column (Wand et al., 2006).

The Anuchin Glacier covers about $34 \mathrm{~km}^{2}$ (length $8 \mathrm{~km}$, width $4.2 \pm 1.2 \mathrm{~km}$ ) and drains into the Lake Untersee oxic basin. The surface velocity of the glacier is about $9 \mathrm{~m} \mathrm{a}^{-1}$ (Wand and Perlt, 1999). This rate was also confirmed by interferometric syntheticaperture radar data (Rignot et al., 2014), accessed via the QGIS Quantarctica package provided by Norwegian Polar Institute.

The adjacent Lake Obersee $\left(3.4 \mathrm{~km}^{2}\right.$, Figure 1) is located $10 \mathrm{~km}$ NNE from Lake Untersee and is also dammed by glaciers on the southern and northern side. Surface melt channels from Obersee to Lake Untersee were not observed but are assumed to exist (Simonov et al., 1985).

Based on a 5-years recording from a Campbell meteorological station at the Lake Untersee shore, the mean annual temperature during the austral summer seasons was $-10.6^{\circ} \mathrm{C} \pm 0.6^{\circ} \mathrm{C}$. The most extreme temperatures throughout the year were $+9^{\circ} \mathrm{C}$ (January 2013) and $-35.2^{\circ} \mathrm{C}$ (July 2012). The number of days above freezing ranged from 7 to 49 days. The prevailing wind direction was south with an average daily maximum of $15 \mathrm{~m}$ $\mathrm{s}^{-1}$ due to katabatic winds from the Wegener ice shelf into the Oasis. The maximum recorded wind speed was $35.7 \mathrm{~m} \mathrm{~s}^{-1}$ (Andersen et al., 2015).

\section{MATERIALS AND METHODS}

\section{Meteorological Records}

During the 2015 summer field season, an additional custom-built weather station recorded wind speed, direction and temperature with a high temporal resolution (1 min interval, 27266 data points). The station was set up in the Aurkjosen Cirque, at the north-western shore of Lake Untersee from November 25, 2015 until December 14, 2015 (Figure 1).

\section{Anuchin Glacier Retreat at Surface and Melt Rate Estimation}

Two aerial images (from 1939 and 1995, provided by the German Federal Agency for Cartography and Geodesy) and a satellite image from 2015 provided by Digital Globe were imported as layers into Adobe Photoshop and subsequently transformed to account for different angles during image acquisition. Then, the scene was cropped to unify all image-excerpts and the glacier-lake boundaries from each image were mapped into evenly spaced 
data points with defined $\mathrm{x}$ and $\mathrm{y}$ pixel coordinates using the software Fiji (Schindelin et al., 2012). The y coordinates from each image were averaged and the resulting differences in pixel location relative to the 1939 position were calculated. The pixel scale was set by counting the number of pixels from geographical features with known dimensions. The length of the glacierlake boundary for each image was measured with the free-hand line tool in Fiji.

The melt rate of the glacier into the lake was estimated by combining data from a bathymetric map (Wand et al., 2006) and the aforementioned calculation of the glacier retreat. Steel et al. (2015) assumed that the glacier forms a straight wall to the lakebed along the glacier-lake boundary. However, we assumed that the glacier-lake boundary is neither a straight wall nor exactly the shape that can be seen at the surface. Hence, our estimates are averaged values from both scenarios.

\section{Cryoconite Hole Coverage}

Images of the glacier surface were recorded with a drone (DJI phantom 2 with 3-axis stabilized gimbal and GoPro Hero 3+) during two flights between 17:00 and 18:00 UTC. In total, 19 images with a resolution of 12 megapixel were analyzed from the medial moraine $(n=10)$, north of the glacier/lake ice ridge $(n=6)$ and white ice patch within the lake ice $(n=3)$. Batch modifications of all histograms with the software Fiji (Schindelin et al., 2012) improved the contrast between cryoconite holes and glacier ice. Also, dark-colored moraine ice was successfully discriminated from cryoconite holes. Next, the images were thresholded which resulted in region of interests (ROIs) with a variety of shapes. Only ROIs with a roundness $>0.6$ were considered in the final calculation where roundness was defined as $4 \times$ Area / $\left(\pi+\right.$ Major Axis $\left.{ }^{2}\right)$.

\section{Sampling}

Sampling took place during expeditions to Lake Untersee in November and December 2008, 2014, and in 2015. All sampling locations depicted in Figures 1, 2 were recorded with a handheld GPS (Garmin GPS 60). To follow potential microbial sources and sinks, we took the following connecting sample types of various origins into account: near-ground air as a source for bioaerosols, glacial ice consisting of cryoconite holes and clear ice, lake ice, lake water, lake sediments as well as surrounding soils. All samples were put in sterile containers and stored in coolers that were buried in snow pits and covered with highly reflective mylar blankets during the field season. After the expeditions, the coolers were shipped to Cape Town, repacked with dry ice and further sent to the respective laboratories. The samples were stored at $-20^{\circ} \mathrm{C}$ until further use.

\section{Cryoconite Holes}

In total, 14 cryoconite holes were collected for this study. Sediments deeper than $\sim 5 \mathrm{~cm}$ were collected with a Kovacs ice corer that was driven by a Bosch Hammer GBH 36V-LI PLUS electrical drill. The core barrel was rinsed with $70 \%(\mathrm{v} / \mathrm{v})$ ethanol and cleaned with an extra ice core that was drilled next to the cryoconite hole to be discarded. Sediments less than $5 \mathrm{~cm}$ deep were collected with a sterile spatula after the ice lid was removed with a sterilized ice axe. Cryoconite hole samples were distinguished into two regions, namely "medial moraine" at the upper part of the glacier medial moraine and "glacier terminus" in proximity of the glacier-lake boundary.

\section{Glacial and Lake Ice Samples}

We sampled glacial ice along the N-S orientated medial moraine (AT_1) and collected additional transects in clean ice $150 \mathrm{~m}$ west (AT_2) and east (AT_3) from AT_1. Each transect consisted of six transect points. The four sampling points closest to the lake were in a distance of $500 \mathrm{~m}$ to each other and the upper two sites were kept each at $1000 \mathrm{~m}$ to the next point.

At each sampling site, three ice cores from the upper $20 \mathrm{~cm}$ of ice were collected with a Kovacs ice corer powered by a 2cycle Tecumseh motor (2014) or a Bosch Hammer GBH 36V-LI PLUS electrical drill with 4 Ah batteries (2015). A custom-made drill guidance system enabled a standardized spatial sampling of triplicate ice cores due to a rotational axis that kept the distance between the ice samples at fixed levels (Supplementary Figure 1).

Additionally, we sampled two one-meter long ice cores from the Lake Untersee ice cover and the so-called "White Ice Patch" which are further referred to as "US" and "WIP," respectively. WIP appears to be glacial ice but is part of the lake ice-cover, south of an ice ridge that separated the glacier from the lake at the surface (Figures 2E,F). Each sample of the $1 \mathrm{~m}$ long ice core was $33 \mathrm{~cm}$ long and categorized as top-middle-bottom sections.

For all drilled samples, post-sampling decontamination procedures (Legrand and Mayewski, 1997; Christner et al., 2005; Doyle et al., 2013) could not be applied due to the brittleness of the ice cores. Instead, a thorough pre-sampling cleaning approach was established: The sampling site was always approached from the leeward side, the core barrel was cleaned with $70 \%(v / v)$ ethanol and subsequently flushed with an original ice sample to be discarded afterward.

\section{Pelagic and Benthic Lake Samples}

Samples of lake water at the anoxic basin were collected in 2008 at 8, 30, 40, 50, and $70 \mathrm{~m}$ with a Niskin bottle. Water samples were kept frozen throughout storage in the field and subsequent transport to the home university with dry ice. Lake sediments from the oxic $(169 \mathrm{~m})$ and anoxic $(100 \mathrm{~m})$ basins were collected with an Ekman dredge connected to a parachute cord. The samples were transported to the campsite and immediately transferred into sterile bags using a baked spatula. Other benthic samples, namely flat mats and pinnacle mats were collected by a scuba diver at a depth of $\sim 30 \mathrm{~m}$ in the oxic basin using methods as described by Andersen et al. (2011).

\section{Soils}

Soil samples were collected with a baked spatula at the southwestern shore of the lake. They were associated with a microbial mat, buried $3 \mathrm{~cm}$ deep in gravel and a gray crust on a rock.

\section{Bioaerosols}

Samples of near-ground air were collected in 2015, at the windward side of the campsite to avoid contamination from the camp itself. Airborne particles were accumulated in a sterile sodium chloride solution (0.9\%) with a Bertin Coriolis- $\mu$ air 


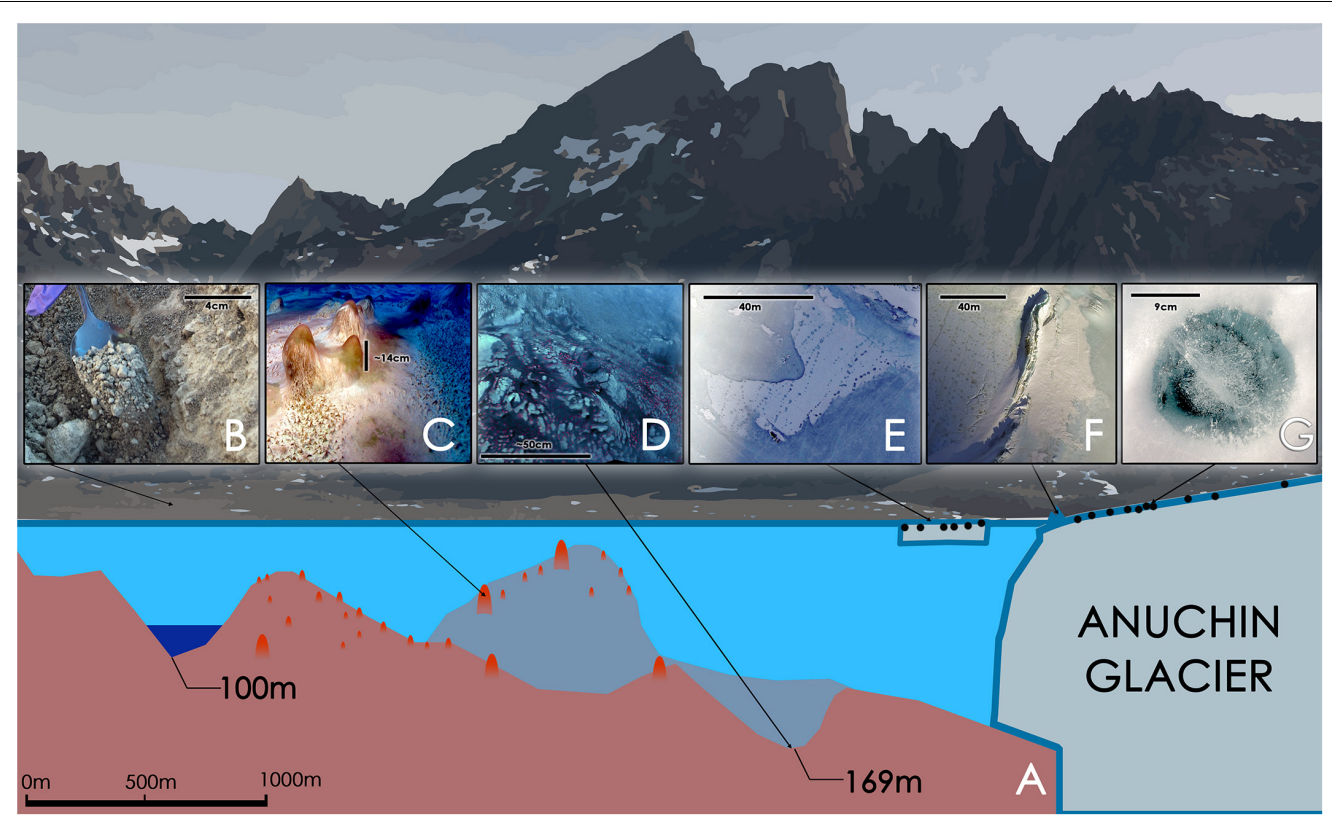

FIGURE 2 | (A) Schematic illustration of Lake Untersee with its 169 m oxic basin and a 100 m anoxic basin [illustration based on (Wand et al., 2006)]. (B) Soil sample. (C) Large conical stromatolites, pinnacle mats and flat mats at a depth of about $24 \mathrm{~m}$. The scale bar is an estimate. (D) Pigmented microbial benthic mats at a depth of $169 \mathrm{~m}$. The scale is an estimate. The pink dots are artifacts that were introduced during a white balance correction. They may indicate a similar surface color as seen in C. (E) "White Ice Patch" - glacial ice integrated in the lake ice containing cryoconite holes that are aligned from NE to SW; the image is oriented with North toward the top of the image. (F) Aerial image of a pressure ridge formed by the Anuchin Glacier (left) at the glacier-lake ice interface. Cryoconite holes are visible as dark dots in the glacier ice. The top left corner is orientated toward north. (G) Typical morphology of an Antarctic ice-lidded cryoconite hole.

sampler. To prevent the liquid from freezing during the sampling procedure, the sampling container was placed in a Nalgene bottle with hot water. After sample collection, the sampling containers were stored with previously collected ice cores that served as a cooling agent. In total, seven samples have been collected over a period of 3 days with a flow rate of $300 \mathrm{~L}^{- \text {min }}$ ranging from 3,000 to 12,000 liters per sample, yielding to $45,000 \mathrm{~L}$ total volume. The captured airborne particles had to be pooled into one sample to gain sufficient DNA content.

\section{Microbial Analysis}

\section{Sample Processing and DNA Isolation}

All samples were thawed thoroughly in the dark at $4^{\circ} \mathrm{C}$. DNA from benthic microbial mats, terrestrial samples and a cryoconite holes was extracted using the PowerSoil ${ }^{\circledR}$ DNA Isolation Kit. PowerWater ${ }^{\circledR}$ DNA Isolation Kit was used for the bioaerosols, ice and water samples following their respective manual's instructions. The DNA content was measured with a Qubit ${ }^{\mathrm{TM}}$ dsDNA HS Assay Kit before 10 ng DNA of each sample were applied as template in subsequent PCR reactions.

\section{Amplicon Generation for Next Generation Sequencing (NGS)}

The 16S rRNA gene amplicons for sequencing were obtained using Illumina-tagged universal primers F515 and R806 as proposed by the Human Microbiome Project and the Earth Microbiome Project (Caporaso et al., 2012) and archaeatargeting primers as proposed by Klindworth et al. (2013). For this approach, we selected the protocol as already proposed by Koskinen et al. (2017) which is based on a nested PCR approach using primers $344 \mathrm{f}$ and $915 \mathrm{r}$ in the first PCR and primer pair S-D-Arch-0519-a-S-15/S-D-Bact-0785-b-A-18 in the subsequent PCR. More information on cycling condition and primer sequences can be found in Koskinen et al. (2017). Library preparation and MiSeq sequencing were carried out at the Core Facility Molecular Biology at the Center for Medical Research, Graz, Austria (Klymiuk et al., 2016).

\section{Next Generation Sequence Analysis}

Raw sequences were pre-processed and filtered using the $\mathrm{R}$ package dada2 (version 1.4.0) according to the proposed processing pipeline (Callahan et al., 2016). Briefly, reads were demultiplexed, forward and reverse reads were quality filtered (min. score: 30 ), merged and the dada2 core algorithm was applied. The taxonomy was assigned to the SILVA 123 database (Quast et al., 2013) and a RSV table was generated. A more detailed workflow can be found in Mora et al. (2016). The downstream analysis was generated using $\mathrm{R}$ (version 1.0.36) as described in the following.

\section{Statistical Analysis}

The RSV table (ribosomal sequence variants) was used to calculate alpha and beta diversity using the R packages Phyloseq (McMurdie and Holmes, 2013) version 1.20.0. To compare microbial diversity in different Lake Untersee environments (oxic and anoxic sediments, benthic microbial mats and pelagic 
samples), alpha diversity was calculated using the Shannon, Observed and Inverse Simpson index. As discussed in McMurdie and Holmes (2014), rarefying counts may result in a high rate of false positives that are differently abundant across samples and thus, no rarefaction was applied. Normal distribution was tested by the Shapiro-Wilk test and significances were tested either by Kruskal-Wallis (if not normal distributed) or an ANOVA (if normal distributed). The Dunn's test was used as post hoc test (Bonferroni corrected). Analysis of beta diversity was performed to examine differences between microbial community structures in Lake Untersee environments. Principal Coordinates Analysis (PCoA) was performed directly on the (to relative abundance transformed) RSV table. Significances were tested using adonis (seed 1) and further confirmed by dispersion tests (permutations: 999). Source tracking was performed using the sourcetracker algorithm as proposed by Knights et al. (2011) and the Venn diagram was generated using the web-based tool InteractiVenn (Heberle et al., 2015).

\section{Negative Controls and Data Storage}

Every step of the analysis included negative controls consisting of blank extractions for each group of samples and negative controls during PCR amplifications. RSVs that overlapped negative controls and samples were removed from the data sets. Sequence data have been deposited in the NCBI database under the accession number SRP145579.

\section{RESULTS}

\section{Glacier Retreat, Melt Rate and Cryoconite Hole Coverage}

The average retreat within 76 years (1939-2015) was $2.37 \mathrm{~m} \mathrm{a}^{-1}$. During the first 56 years (1939-1995) the glacier retreated on average by $1.16 \mathrm{~m} \mathrm{a}^{-1}$ and increased up to $5.76 \mathrm{~m} \mathrm{a}^{-1}$ during the last 20 years (1995-2015). Combining these calculations with data from a bathymetric map of Lake Untersee (Wand et al., 2006), the melt water contribution to the lake within 76 years was $7.83 \times 10^{7} \pm 2.07 \times 10^{7} \mathrm{mł}$ which equaled an average melt rate of $1.03 \times 10^{6} \pm 2.72 \times 10^{5} \mathrm{ml} \mathrm{a}^{-1}$. Between 1995 and 2015, the rate increased 2.34-fold compared to the long-term average, meaning that $63.9 \%$ of the total melts happened during the last quarter of this 76-year period. The long-term annual melt input corresponded to $1.18 \times 10^{-1} \pm 3.12 \times 10^{-2} \%$ of the current estimated lake volume $(0.872 \mathrm{~km})$. Further, the length of the surface glacier-lake boundary smoothened and therefore decreased by $2.85 \mathrm{~km}$. About $82 \%$ of this reduction happened between 1995 and 2015. The position of the Anuchin Glacier for the years 1939, 1995, and 2015 is depicted in Figure 3.

The cryoconite holes coverage on the Anuchin Glacier was $3.46 \pm 2.34 \%$ on average. The highest density was observed near the glacier-lake interface at the SW part of the glacier $(6.36 \pm 0.98 \%)$ and the lowest coverage was observed along the medial moraine $(1.73 \pm 0.36 \%)$.

Assuming an average cryoconite layer thickness of $1 \mathrm{~cm}$, we estimated that the long-term (1939-2015) average contribution to the lake ranged between 3.69 and $13.56 \mathrm{~m} \mathrm{a}^{-1}$ and from 8.96 to $32.94 \mathrm{~m} \mathrm{a}^{-1}$ in recent years (1995-2015), respectively.
The maximum volumetric portion of cryoconite to the annual melt was $1.32 \times 10^{-3} \%$ on average within 76 years, representing $1.56 \times 10^{-6} \%$ of the present estimated lake volume.

\section{Wind and Temperature Regime at Lake Untersee}

About $77 \%$ of the time local winds from 90 to $160^{\circ}$ were recorded during a 20-day period (Supplementary Figure 2). The highest average wind speeds ( 1 min interval, $8 \mathrm{~m} \mathrm{~s}^{-1}$ ) and maximum wind speed $\left(24.6 \mathrm{~m} \mathrm{~s}^{-1}\right)$ were associated with the prevailing wind directions. Average hourly wind speeds above $7 \mathrm{~m} \mathrm{~s}^{-1}$ occurred only between $02: 00$ and 10:00 and the average temperature was $-0.08^{\circ} \mathrm{C}\left(\min .-8.3^{\circ} \mathrm{C}, \max .7 .2^{\circ} \mathrm{C}\right)$.

\section{The Bacteriome of Lake Untersee Oasis}

For bacterial community profiles, the prevailing information was grouped into seven different habitats: "Air" (air sample), "Terrestrial" (buried mat and crust from a rock), "Pelagic" (water column of Lake Untersee), "Benthic" (benthic microbial mats and sediments from Lake Untersee), "Lake ICE” (lake ice from Lake Untersee), "Glacier ICE" (surface ice of Anuchin Glacier) and "Cryoconite" (cryoconite holes from Anuchin Glacier). Amplicon sequencing resulted in a total of 1,414,290 read counts, including 4,772 taxonomic observations in 52 samples. The amplicon read counts for all samples are depicted in Supplementary Figure 3, ranging from 3,545 counts in sample "Cryoconite 5" to 50,838 counts in sample "WIP_bottom."

Overall, signatures of 42 bacterial phyla were detected, whereas most of the RSVs were affiliated with Proteobacteria (35.4\% of all RSVs), followed by Actinobacteria (17.9\%), Cyanobacteria (13\%) and Firmicutes (7.6\%). The highest percentage of reads was assigned to the bacterial genera Methylobacterium (1.9\% of all RSVs), Reyranella (1.7\%), Sphingomonas (1.8\%), Polaromonas (1.8\%) and Acinetobacter (2.4\%). Tychonema (6.7\%), Chamaesiphon (2.5\%), and Leptolyngbya $(2.7 \%)$ comprised most affiliated reads for the phylum Cyanobacteria. An overview of the most abundant phyla across the sampling sites is depicted in Figure 4.

The bacterial alpha diversity was calculated using the indices Observed, Shannon and InvSimpson and is depicted in a boxplot (Figure 5). Data for the Observed and InvSimpson indices were not normally distributed (Shapiro-Wilk Test: $p<0.05)$ and differed significantly $\left(p=1.078 \times 10^{-4}\right.$ and 0.04 , respectively; Kruskal-Wallis Test). This was also true for the normally distributed dataset observed for the Shannon index $\left(p=6.68 \times 10^{-5} ;\right.$ ANOVA $)$.

There were significant differences between the groups “GLACIER ICE” / "GLACIER CRYOCONITE" and "GLACIER ICE" / "LAKE BENTHIC" when using the Observed index $\left(p=3.261232 \times 10^{-5}\right.$ and $4.102203 \times 10^{-2}$, respectively; Dunn's Test, the $p$-values were adjusted using the Bonferroni method). In total, 4 groups were significantly different when observing the Shannon Index ("GLACIER ICE" / "GLACIER CRYOCONITE" $p=0.001$; “LAKE BENTHIC" / "LAKE ICE" $p=0.004$; "LAKE BENTHIC" / "GLACIER CRYOCONITE" $p=0.017$; “LAKE ICE" / “GLACIER ICE” $p=0.002$; Tukey's 


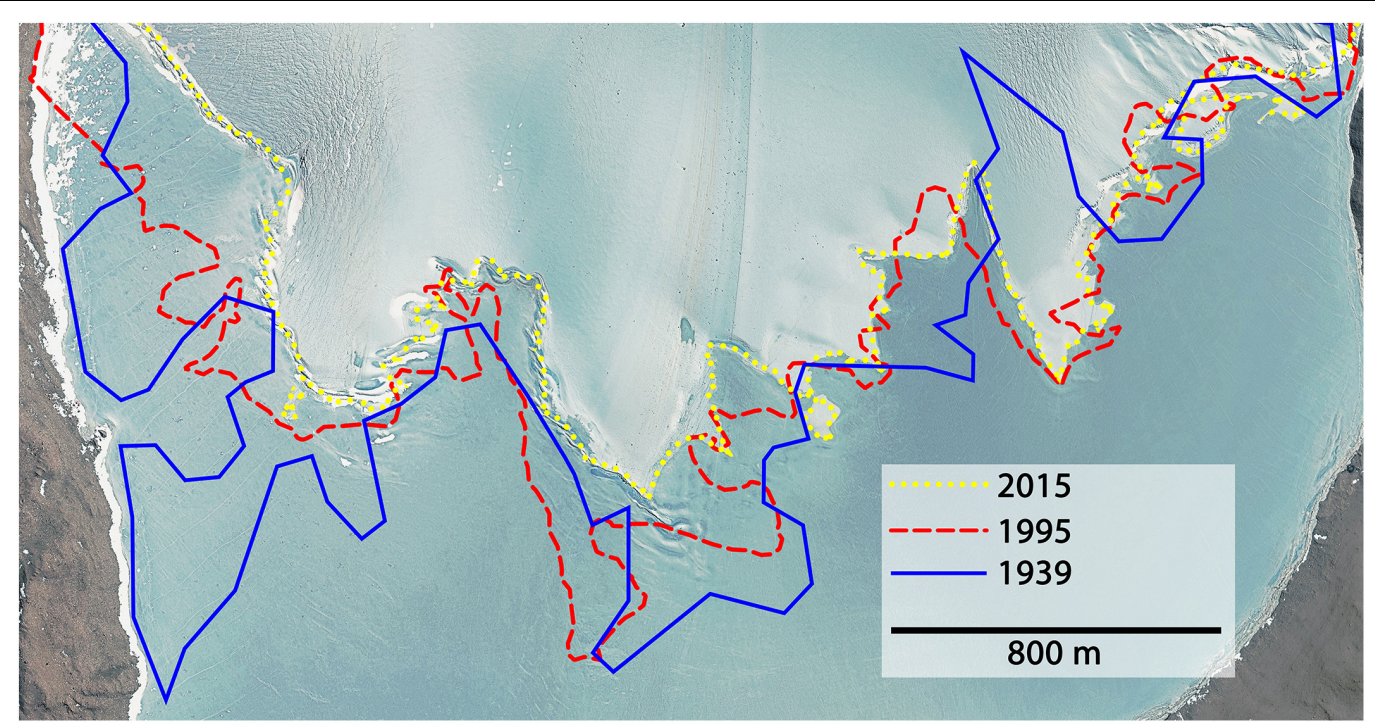

FIGURE 3 | The glacier-lake boundaries are shown for the years 1939 (blue), 1995 (red), and 2015 (yellow). Satellite image @ DigitalGlobe, Inc. Provided by NGA Commercial Imagery Program.

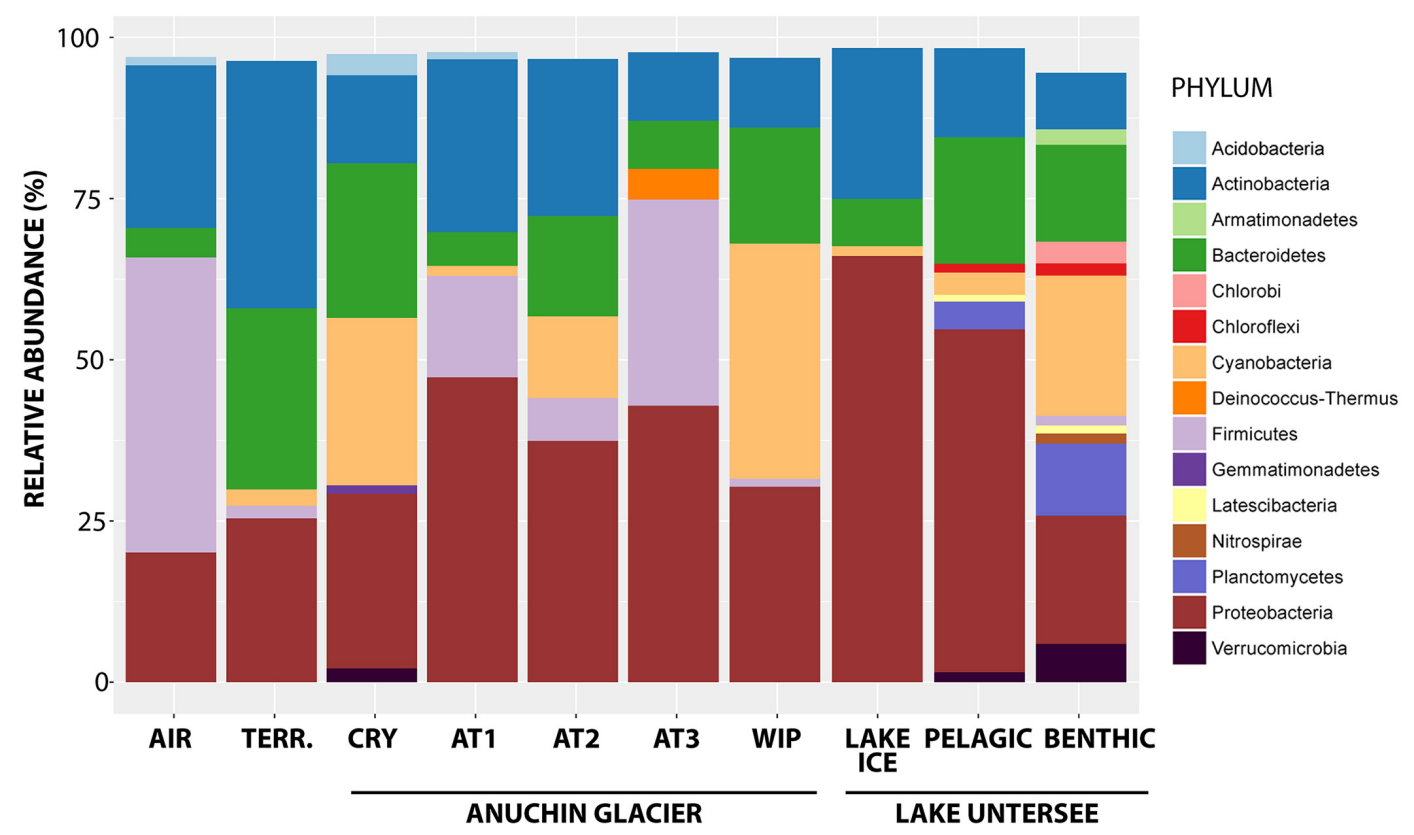

FIGURE 4 | Bacterial phyla from the Anuchin Glacier, Lake Untersee and its surroundings. TERR, terrestrial samples; CRY, cryoconite holes; AT1-3, parallel ice transects along Anuchin Glacier; WIP, white ice patch in Lake Untersee. Sequences unidentified at the genus level and low abundant phyla (abundance $<1 \%$ ) were removed.

post hoc test, $p$-values were adjusted using Bonferroni). The pooled air sample had to be excluded from statistical analysis.

Regarding the beta diversity, the samples clustered according to their grouping and were significantly different from each other (Figure 6, ANOSIM: 999 permutations, $p<0.001$ ). Most of cryoconite holes from the medial moraine overlapped with lake samples while cryoconite holes from the glacier terminus were rather isolated from other lake samples. Except for the lake ice cover, lake samples also clustered with terrestrial samples. The glacier ice formed three distinct clusters; two of them were associated with white ice patch samples and one with the air sample, respectively.

We observed 12 out of 1247 genera $(0.96 \%)$ that occurred in all habitats. They were affiliated with Tychonema, Leptolyngbya, Opitutus, Gemmatimonas, Brevundimonas, Pedobacter, Cryobacterium, Flavobacterium, Gemmata, Roseomonas, 


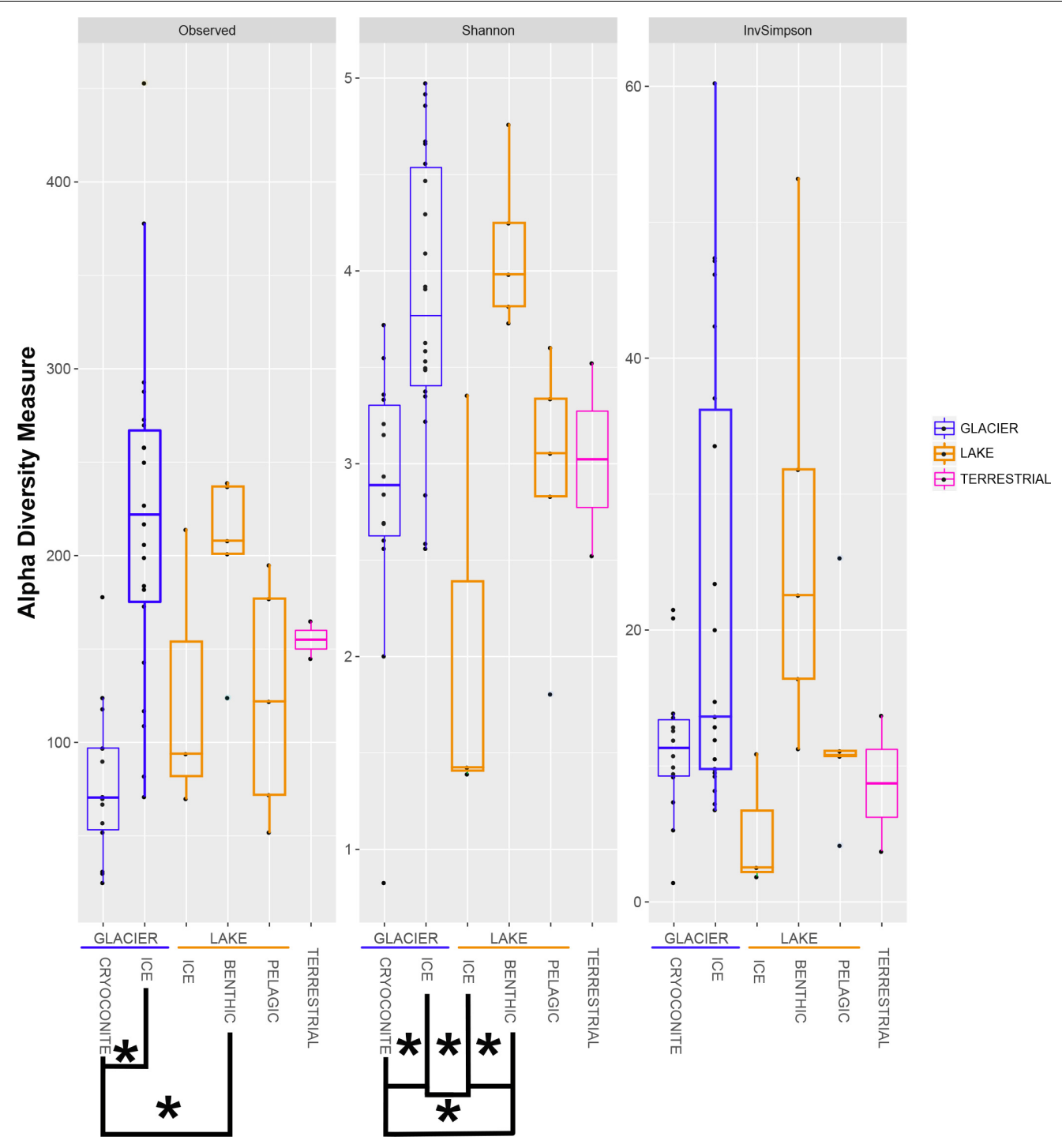

FIGURE 5 | The alpha diversity indices Observed, Shannon and InvSimpson are shown in boxplots. All samples are grouped into similar habitats. Significant differences are marked with clamps and stars.

Blastocatella, and Novosphingobium. Microbial communities in aerosols harbored 142 genera and shared 96 of them (67.6\%) with glacier ice communities and 79 (55.6\%) with cryoconite holes, respectively. The supraglacial environment contained in total 713 genera, 112 of them $(10.55 \%)$ were present in both, glacial ice and cryoconite holes while 38 genera $(3.58 \%)$ were exclusive to cryoconite holes and 563 genera (42.47\%) were only found in glacial ice. From 108 OTU's that were identified in terrestrial sources 36 (33.3\%) of them were also discovered in cryoconite holes, glacial ice and the lake. The lake harbored 284 different genera. Lake sediments and the water column shared $62(21.8 \%)$ of them. In the lake and on the glacier, 177 genera (21.5\% of genera affiliated with the lake) were identical with glacier affiliated genera (Figure 7).

We focused on the supraglacial habitats cryoconite holes and glacial ice as they were different from each other in richness and diversity. Taxa with significantly different abundances were determined using the Mann-Whitney test (with FDR - false discovery rate correction for multiple comparisons). In total, 92 RSVs were significantly different abundant $(p<0.05)$. The majority were abundant in the glacier ice but not abundant in cryoconite holes. Most of the RSVs could not be assigned to any known taxon.

Since cyanobacteria merit special emphasis in cryospheric habitats (Vincent, 2000; Namsaraev et al., 2010; Chrismas et al., 2015) we counted RSVs assigned to this phylum and tested for significant differences in abundance for the groups "GLACIER ICE," "GLACIER CRYOCONITE," "LAKE BENTHIC," "LAKE PELAGIC" and "Lake ICE" (Figure 8). The cyanobacterial abundance accounted for 13\% in the entire bacteriome with the highest presence in the groups "GLACIER CRYOCONITE" $(25.4 \%$ of the overall cyanobacterial affiliated RSV counts), followed by the group "LAKE BENTHIC" (21.4\%) and "GLACIER ICE" (13.6\%). 


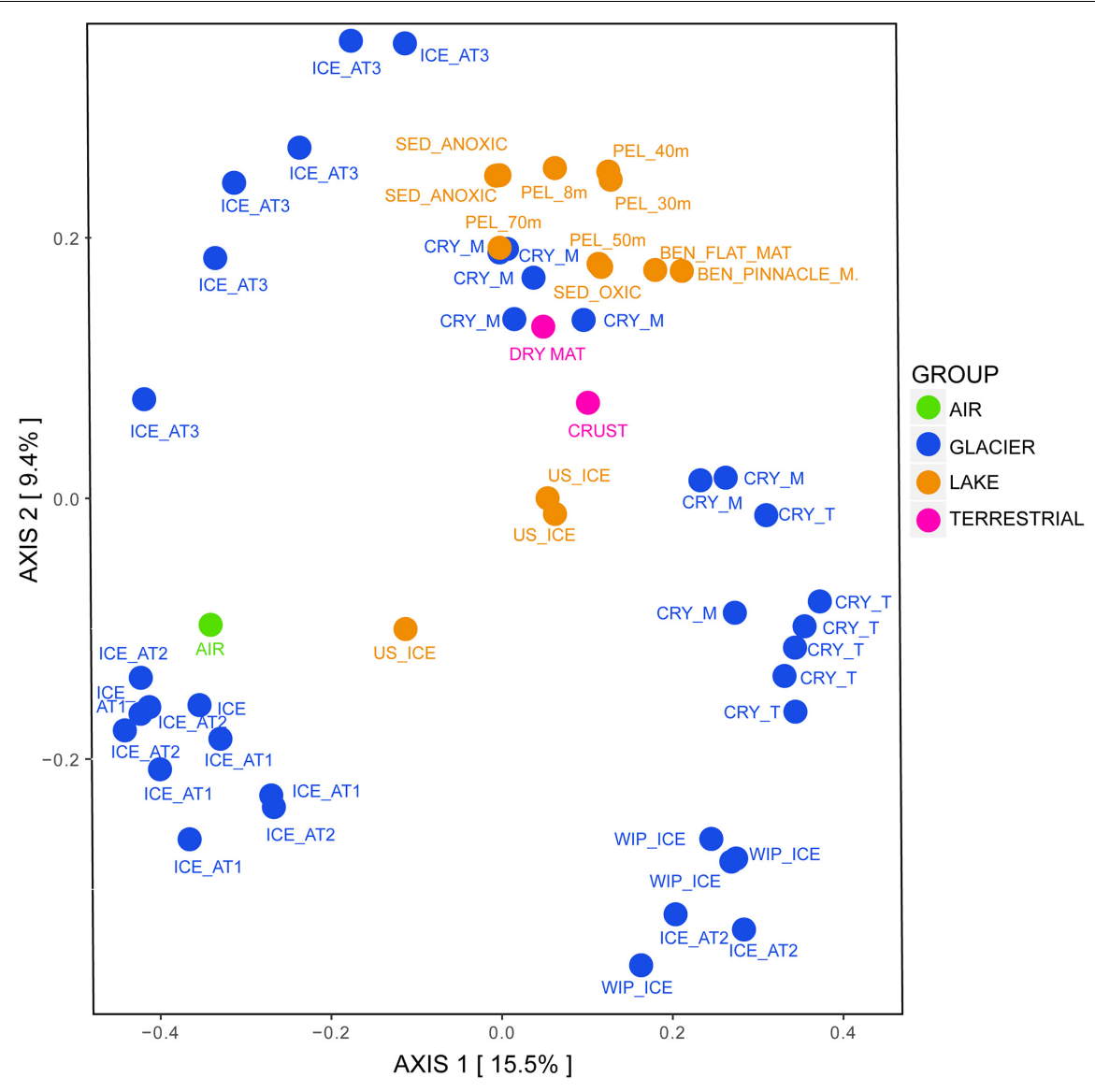

FIGURE 6 | Bacterial beta diversity in the Untersee Oasis displayed as PCoA plot using Bray-Curtis distance matrix. The habitats "Air," "Anuchin" (glacier), "Lake" (Untersee), and "Terrestrial" are color coded. CRY_M, Cryoconite holes from the medial moraine; CRY_T, Cryoconite holes from the glacier terminus; SED, Sediment; PEL, Pelagic; BEN, Benthic. Further differentiation is described in the Section "Materials and Methods."
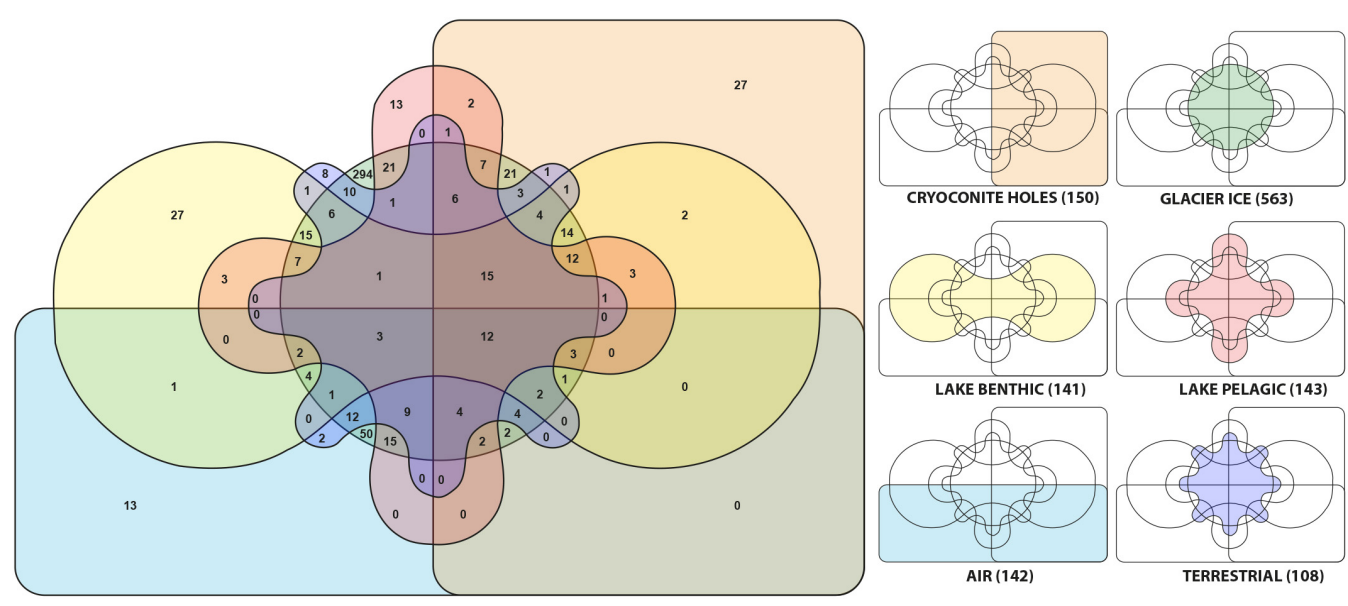

FIGURE 7 | Genera from six different habitats are displayed in a Venn-diagram. For clarification, the colors and positions of each habitat are separately shown as mini diagrams. The numbers in brackets indicate the number of genera at each location.

Fewer cyanobacterial affiliated RSVs were detected in the samples "LAKE PELAGIC" (3.4\%), TERRESTRIAL (2.6\%) and "AIR" (0.9\%).
Three genera were significantly different abundant: Chamaesiphon, Pseudanabaena and RSV belonging to an unidentified genus (Mann-Whitney $U$ Test, FDR corrected, 


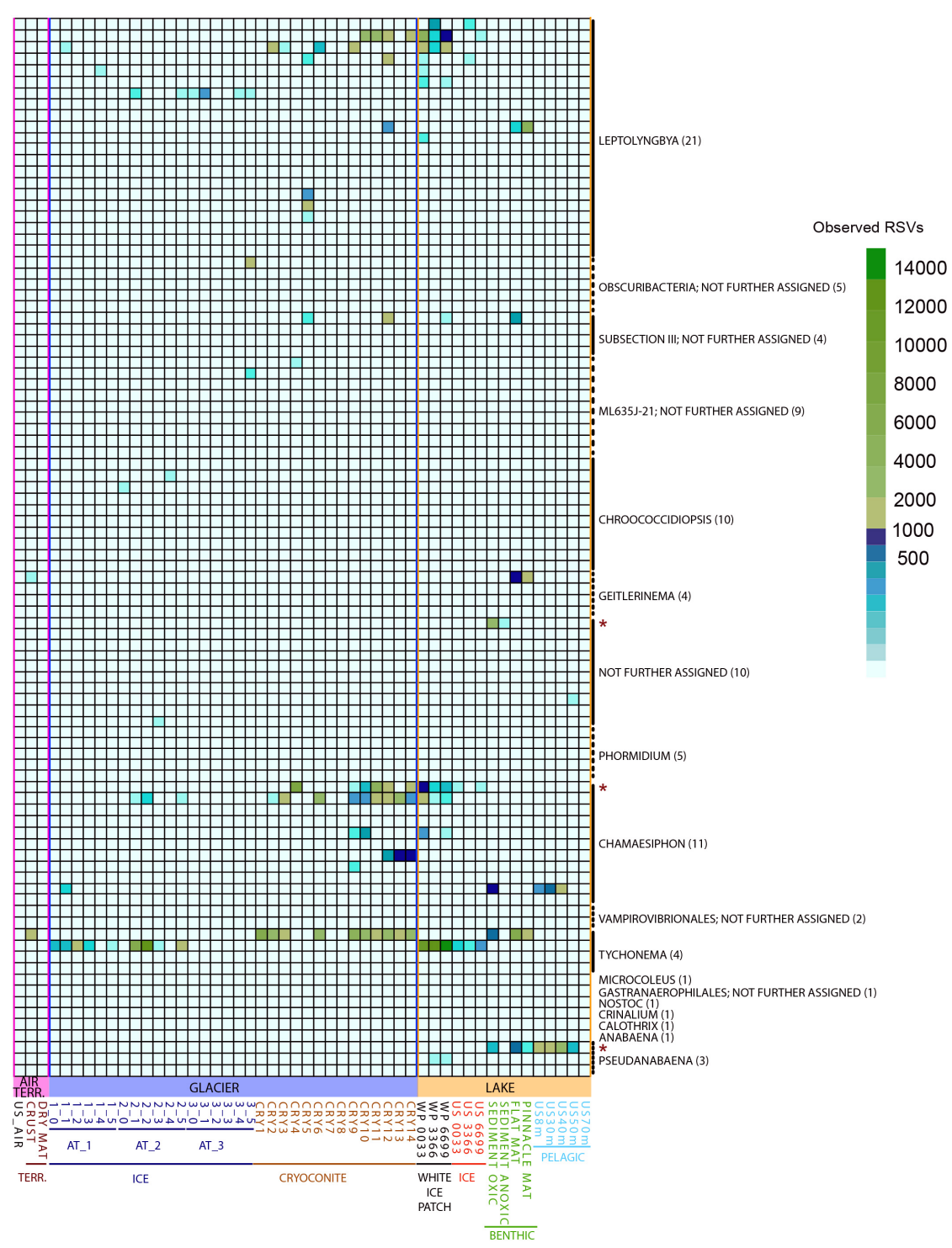

FIGURE 8 | Observed RSVs belonging to the phylum Cyanobacteria (affiliated to genus level, numbers of RSVs in brackets) in individual samples, depicted as heatmap. Significantly different abundant RSVs are marked with a red star.

$p<0.05)$. Here, the highest amount of genus-assigned RSV counts was affiliated to Chamaesiphon in the group "GLACIER CRYOCONITE" $(9.8 \%$ of all cyanobacterial affiliated RSV counts) and Pseudanabaena in the group "LAKE PELAGIC" (2.5\%).

\section{The Archaeome of Lake Untersee Oasis}

In total, 13 samples did not comprise any RSV affiliated to archaea (amongst them the "AIR" sample and most of the "LAKE ICE" samples). From all other samples, 185,004 archaeal RSV counts were obtained. Exclusively, all RSVs were affiliated to Euryarchaeota and the highest amount of all archaeal RSV counts was classified as Methanomicrobia (51.8\%), followed by Halobacteria (43.2\%) and low numbers of Thermoplasmata (>5\%), Methanobacteria and Thaumarchaeota (both > 1\%).
Methanogens were exclusively detected in the groups "LAKE ICE" and "LAKE BENTHIC" as well as a high majority of unassigned MethanobacterialesSMS-sludge 7 (almost $70 \%$ of all methanogen-related affiliated RSV counts). Methanosaeta (almost 16\%) and Methanocellaceae (Rice Cluster 1, almost 12\%) comprised also a high RSV count, while low abundant RSVs were affiliated to Methanobrevibacter and Methanosarcina $(<1 \%)$ (Figure 9).

The archaeal alpha diversity was calculated as described in the section "bacterial alpha diversity." The highest diversity and richness were detected in the group "LAKE BENTHIC" followed by "GLACIER ICE" and "GLACIER CRYOCONITE." The groups "TERRESTRIAL" and "LAKE ICE" comprised a very low diversity and almost all samples 


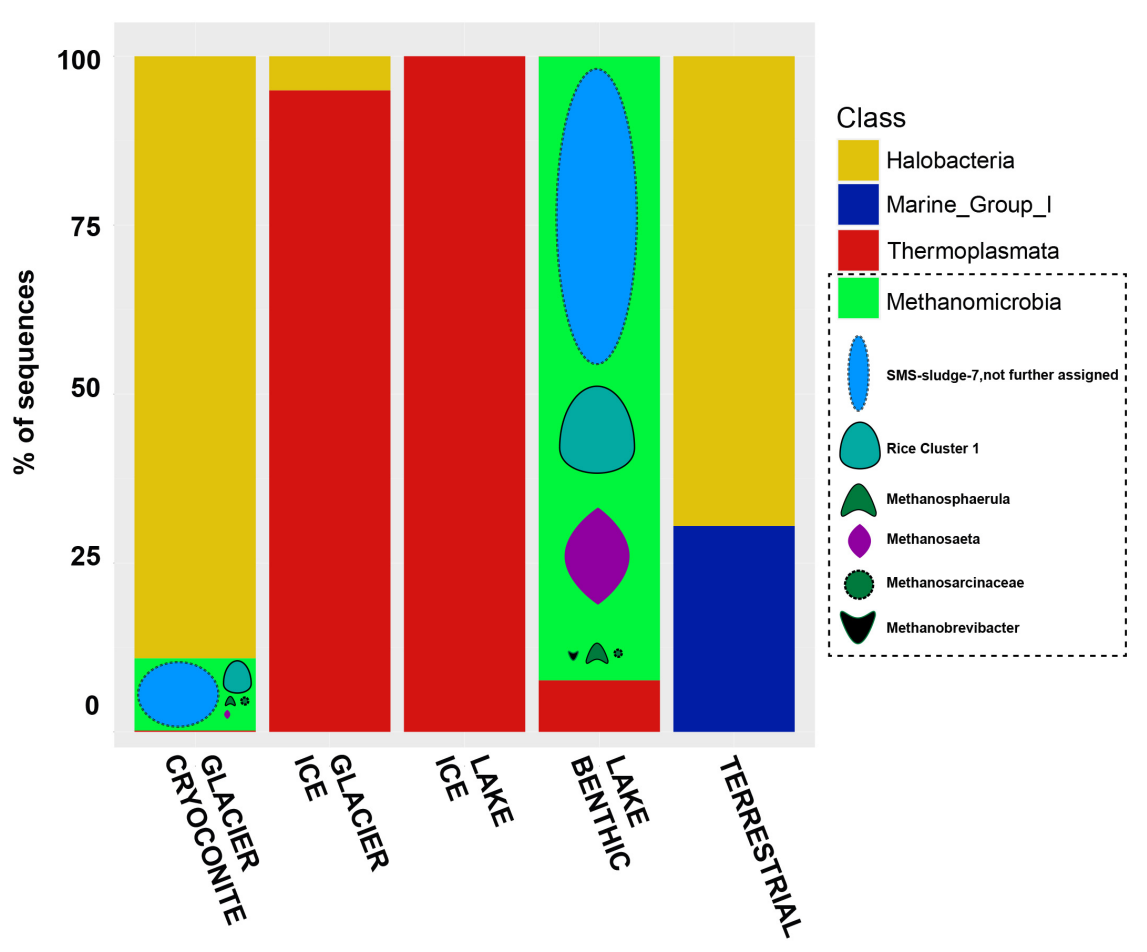

FIGURE 9 | Bar chart of archaeal sequences assigned to their respective habitats. Methanomicrobia are further classified into the groups SMS-s/udge-7, Rice Cluster 1, Methanospaerula, Methanosaeta, Methanosarcinaceae, and Methanobrevibacter.

within these groups did not contain any Archaea at all (Supplementary Figure 4). Statistical analyses as performed for the bacterial dataset were not applicable for the archaeal dataset. The low abundance and/or absence of archaeal related RSVs in many samples violated the conditions for these analyses.

Principle Coordinates Analysis showed that samples that contained archaeal sequences formed three separate clusters. All ice samples ("GLACIER ICE" and "LAKE ICE") lined up in the same area and showed the largest distance on the $x$-axis (51.4\%) to other assemblages, namely "GLACIER CRYOCONITE" and lake sediments from the group "LAKE BENTHIC." The remaining "ANUCHIN CRYOCONITE," “TERRESTRIAL", and "LAKE BENTHIC" samples formed a third cluster (Figure 10). An analysis of similarity as done for the bacterial beta diversity was not applicable for the archaeal dataset due to the absence of Archaea in too many samples.

\section{Sourcetracking}

To estimate source environments for the microbial distribution, we applied a source tracking algorithm (Knights et al., 2011). Geographically, Lake Untersee habitats "LAKE BENTHIC" and "LAKE PELAGIC" represented the "sink." Almost all configurations in this estimate were not assigned to a known source location (Figure 11). However, the location "GLACIER CRYOCONITE" was identified as the inoculation source of highest impact amongst all known locations, contributing up to $36 \%$ to the sink environment.

\section{DISCUSSION}

\section{Biotic Transfer From the Anuchin Glacier to Lake Untersee}

A diverse range of habitat types at the Lake Untersee Oasis host microbial life including glacier surfaces, ice-free areas, and a perennially ice-covered lake with its pelagic and benthic zones. These refugia are geographically connected as aerial and local depositions inoculate cryoconite holes on the glacier surface and subsequently colonize Lake Untersee. Generally, extremely short periods in the year provide subsurface melt water within cryoconite holes that ensure biotic exchange and the surrounding glacial ice. However, sub-surface glacial melt into Lake Untersee exists throughout the year with sub-annual varying rates (Steel et al., 2015).

We used a Bayesian source tracking algorithm (Knights et al., 2011) to estimate the proportion of source habitats (supraglacial ice, cryoconite holes, soils, aerosols) to a sink environment (benthic and pelagic zones within Lake Untersee) with potential unknown sources such as englacial and subglacial zones. We showed that the proportion of cryoconite holes as source for benthic microbial mats in Lake Untersee made up to $36 \%$ while all other sampled source habitats as such were negligible (Figure 11). Considering that the estimated average annual volumetric contribution of cryoconite to the total melt volume was $1.13 \times 10^{-3} \%$, the proportion of cryoconite hole communities as source environment appeared to be substantial. 


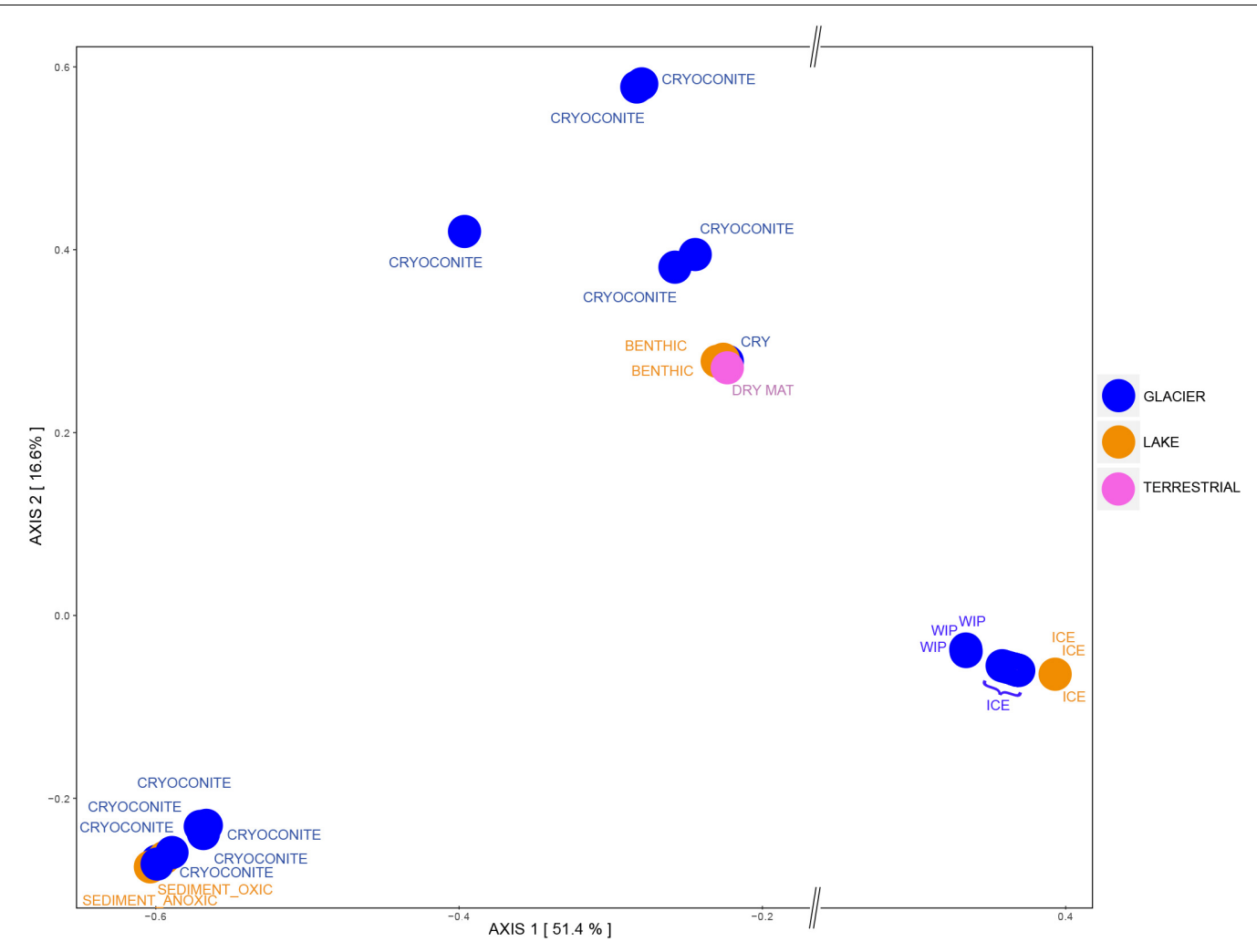

FIGURE 10 | Archaeal beta diversity at Lake Untersee Oasis. Habitats are color-coded and further description is depicted as text: CRY, Cryoconite holes; WIP, White ice patch. For a better visualization, an axis break on the $x$-axis was introduced.

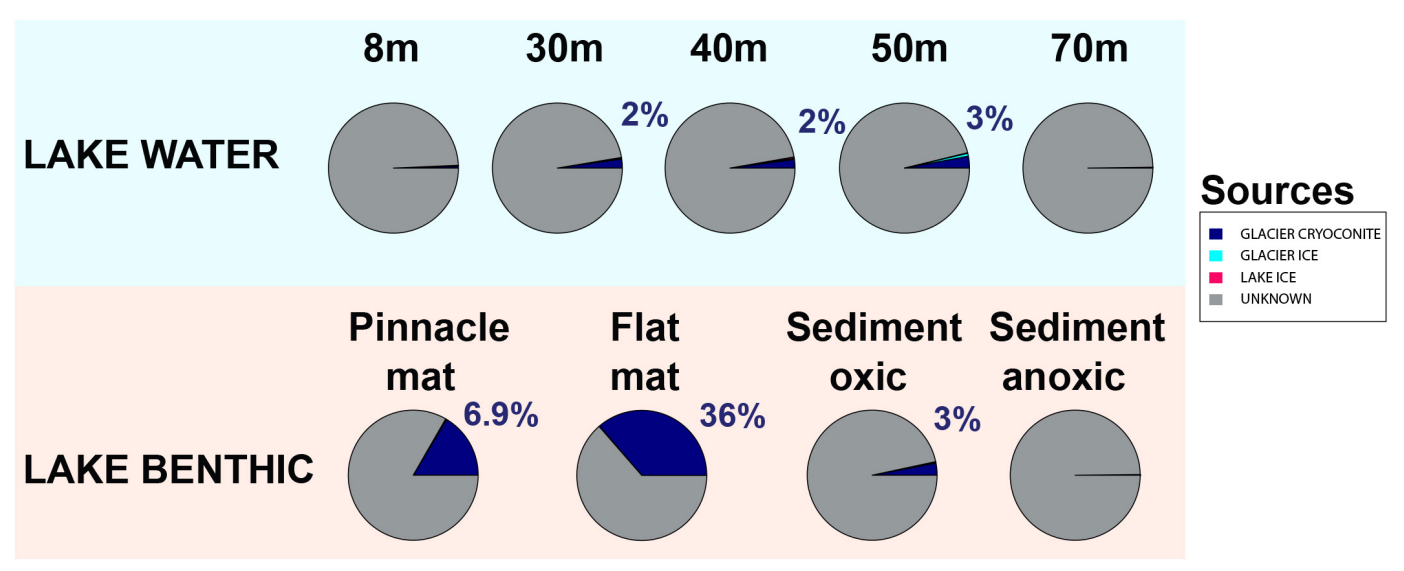

FIGURE 11 | Defining potential sources of the microbial community using the Bayesian community-wide culture-independent microbial source tracking algorithm. Most source environments remained unknown (depicted in gray). Most of the known source environments belonged to the group "GLACIER CRYOCONITE."

Most biotic sources that inoculated Lake Untersee benthic and pelagic zones were not identified in this study and the proportion of known source environments differed across the sink samples. We expected biota entering the lake being present in the water column and benthic zones but pelagic microbial communities did not appear as an important sink environment. Considering that the lake was not permanently ice covered (Schwab, 1998) until at least 500 years ago (Wand and Perlt, 1999), it is likely that it was primarily colonized before the formation of today's perennial ice cover. Hence, a limited biotic transfer into the lake caused by the presence of an ice cover at the time of sampling would explain why the waterbody was not classified as an important sink environment. Also, our sampling efforts only allowed a temporal snapshot of the microbiome of Lake Untersee Oasis. In contrast, high estimates of cryoconite biota as source for the benthic zone may be partly caused by so-called 
"lift-off" microbial mats that reinoculate the Anuchin Glacier and hence might have the fate of being recycled in this loop. Benthic microbial mats form gas bubbles that increase the buoyancy and therefore disrupt the mats. Consequently, they float upward and integrate into the lake ice cover as the ice thickens from the bottom and resurface as the lake ice cover ablates. Local winds measured by Andersen et al. (2015) and during our expedition (Supplementary Figure 2) would predominantly disperse these mats from the lake surface toward the Anuchin Glacier. This liftoff effect was observed at Lake Untersee and is also known from other Antarctic perennially ice-covered lakes (Parker et al., 1982; Moorhead et al., 2003). However, it is not clear whether this mode of dispersal played a significant role at our study site.

\section{Microbial Communities in Source Habitats for Lake Untersee Microbiome}

Bioaerosol samples from Lake Untersee Oasis were dominated by Firmicutes, Proteobacteria and Actinobacteria. Cyanobacteria, which are known to be deposited as bioaerosols (Michaud et al., 2012), accounted only for $0.9 \%$ of the community. In comparison, bioaerosols from the Antarctic Miers Valley were also dominated by Firmicutes followed by Acidobacteria, Planctomycetes and Actinobacteria (Bottos et al., 2014). Further, we found members of the genera Staphylococcus, Bacillus, Corynebacterium, Micrococcus, Streptococcus, and Neisseria that are commonly reported in the literature of Antarctic related and general bioaerosol studies (Cuthbertson and Pearce, 2017).

Fluxes of bioaerosols depend on parameters such as wind speed and direction (Crawford et al., 2017) and vary at a temporal scale (Fierer et al., 2008; Šabacká et al., 2012). At Lake Untersee, the prevailing wind direction and the highest wind derived from the south (Andersen et al., 2015). Also, high wind velocities were measured from the Aurkjosen Cirque where our temporary weather station was set up during the field season 2015. There, the strongest winds and the dominant wind direction were recorded from S-SE (Supplementary Figure 2). Thus, local aerosolized terrestrial sources from the southern part of the Untersee Oasis and from Aurkjosen Cirque are likely to be dispersed on the ice surface of the Anuchin Glacier.

Local wind systems may influence not only microbial communities in cryoconite holes but also induce the formation of these habitats. For instance, a glacier terminating into the southern part of Lake Obersee (Figure 1) lacks cryoconite holes (personal observation). There, the predominant wind direction (presumably from the East) may not promote the allocation of a sufficient amount of local terrestrial sources onto the glacier. There, the catchment area with potential dust sources in the windward direction of the glacier is small, compared to the setting at the Anuchin Glacier. Whether these local wind systems also influence the composition of microbial communities in glacial ice is unknown and requires further investigation.

For soil samples, the dominant phyla from the Untersee Oasis were Actinobacteria, Bacteroidetes, Proteobacteria,
Cyanobacteria, and Firmicutes. In comparison, Dry Valley soil bacterial communities showed a higher diversity, consisting of Proteobacteria, Actinobacteria, Acidobacteria, Gemmatimonadetes, Bacteroidetes, Deinococcus-Thermus, Cyanobacteria, Planctomycetes, Chloroflexi, and less abundant other phyla (Cary et al., 2010).

Aerial dispersal of biota may be one of the main vectors for the inoculation of isolated and remote habitats (Bowman and Deming, 2017). The same assumption was made for cryoconite holes from the McMurdo Dry Valleys because the adjacent surroundings did not reflect the biotic composition in these mini-ecosystems (Porazinska et al., 2004). Also, communities in cryoconite holes and ice-marginal environments from Arctic glaciers (Edwards et al., 2013b) and from a glacier in the Italian Alps (Franzetti et al., 2017) were distinct.

Biotic input from melting ice surrounding cryoconite holes is an underestimated source for cryoconite hole communities as already proposed by Hodson et al. (2013). Cryoconite hole microbial communities from the Untersee Oasis consisted of Proteobacteria, Cyanobacteria, Bacteroidetes, Actinobacteria, Acidobacteria, Verrucomicrobia, and Gemmatimonadetes. Communities from the same habitat type at the Taylor Glacier in the McMurdo Dry Valleys harbored the same dominating phyla as we have identified at the Untersee Oasis but their relative abundance varied (Christner et al., 2003). Further, Cameron et al. (2012) emphasized that Gemmatimonadetes related sequences were present in cryoconite holes from the Vestfold hills but absent in samples outside Antarctica, including Greenland, Svalbard and Norway. We also have identified Gemmatimonadetes related sequences in $78 \%$ of all cryoconite hole samples from a single glacier and Christner et al. (2003) also identified this phylum in Antarctic cryoconite holes from Canada Glacier.

Bare ice is considered as a habitat supporting active microbial life (Edwards and Cameron, 2017). Lake Untersee ice samples were dominated by Proteobacteria, Actinobacteria, Bacteroidetes, and Cyanobacteria. In contrast, samples from the white ice patch within the Lake Untersee ice cover were dominated by Cyanobacteria, Proteobacteria and Bacteroidetes. In both types of sediment-free ice samples, the cyanobacterial genera Tychonema, Leptolyngbya and Chamaesiphon were dominant. In contrast, Cyanobacteria affiliated with the genera Phormidium, Chamaesiphon, Leptolyngbya, and other taxonomical not assigned Cyanobacteria in the sediment rich lake-ice cover of Lake Bonney in the Antarctic Dry Valleys comprised $20 \%$ of the microbiota (Priscu et al., 1998).

Surface ice samples from the Anuchin Glacier were divided into three transects, namely the medial moraine (AT1) that was flanked by two parallel transects (AT2, AT3) with clear ice. We found Proteobacteria, Actinobacteria, Firmicutes, Bacteroidetes, and Cyanobacteria to be dominant in all glacial ice samples. Within the phylum Proteobacteria, Betaproteobacteria were dominant in the medial moraine (AT1), whereas Gammaproteobacteria (AT2) and Alphaproteobacteria (AT3) were more abundant in the clean-ice parallel transects. 
Genera belonging to Cyanobacteria that were present in the lake ice and the white ice patch were also discovered in at least one of the glacier transect points. Within Cyanobacteria, Chroococcidiopsis was found in AT1 and AT2 while the genera Geitlerinema, Microcoleus, Nostoc, Phormidium, and Pseudanabaena were mainly present along the medial moraine (AT1), indicating that different genera of Cyanobacteria prefer specific local conditions or that biotic sources differ among transects.

Cryoconite holes are considered as microbial hotspots in supraglacial Arctic environments due to a high biodiversity (Edwards et al., 2013a; Cook et al., 2016). Contradictory, bacterial alpha diversity from cryoconite holes at the Anuchin Glacier was significantly lower compared to the surrounding supraglacial ice which had the highest diversity from all Lake Untersee Oasis habitats (Figure 5). The presence of an ice-lid on Antarctic cryoconite holes and hence a limited exchange with adjacent habitats may explain these discrepancies. However, limitation in NGS analysis includes uneven sample depth and full certainty on actual microbial communities cannot be provided. Further analyses need to be carried out in order to gain a more accurate picture.

Microbial assemblages in cryoconite holes and the glacier ice were significantly different (Figure 6). The most relative abundant and significant contributors in cryoconite holes (7.3\%) and surface ice (5.65\%) were taxonomically not assigned and except for Actinobacteria in cryoconite holes and Thermoleophilia in glacier ice, less than $50 \%$ of the genera within the significantly different classes (Thermomicrobia, Rubrobacteria, Negativicutes, Gammaproteobacteria, Erysipelotrichia, Clostridia, Betaproteobacteria, Bacteroidia, Bacilli, and Alphaproteobacteria) could not be assigned either. Cameron et al. (2016) compared supraglacial communities on a larger spatial scale across the Greenland ice sheet and found that the sample type (cryoconite vs. ice) accounted only for $2.3 \%$ of the total variability in supraglacial microbial community composition.

Pelagic microbial communities from Lake Untersee were dominated by Proteobacteria, Bacteroidetes, Actinobacteria, Planctomycetes, and Cyanobacteria. In comparison, within three interconnected lakes located in the nearby Schirmacher Oasis, Chloroflexi was among the most abundant phyla and another series of connected lakes from the same area was rather dominated by Firmicutes than by Bacteroidetes (Huang et al., 2014). The authors concluded that each series of lakes can be considered as one large lacustrine ecosystem due to their interconnectivity. Further, Lake Tawani, another waterbody of the Schirmacher Oasis, harbored Proteobacteria and Bacteroidetes as the other lakes did, but members of the phyla Verrucomicrobia, Candidate Division TM7, and Planctomycetes (Huang et al., 2013) were absent in the interconnected lakes studied by Huang et al. (2014).

We analyzed benthic microbial mats from a depth of about $30 \mathrm{~m}$, sediments from both an anoxic basin at $100 \mathrm{~m}$ and from an oxic basin with a maximum depth of $169 \mathrm{~m}$. As reported elsewhere (e.g., Andersen et al., 2011; Wilkins et al., 2013; Mackey et al., 2015; Findlay and Battin, 2016; Koo et al., 2017a,b; Tanabe et al., 2017) benthic microbial mats are usually dominated by Cyanobacteria. Lake Untersee benthic microbial mat samples (flat mat and pinnacle mat) were no exception from previous observations and harbored Cyanobacteria, Proteobacteria, Bacteroidetes, Planctomycetes, Verrucomicrobia, and Actinobacteria. In contrast, the main phyla in the oxic sediment belonged to Bacteroidetes, Proteobacteria, Cyanobacteria, Actinobacteria, and Planctomycetes. In the anoxic sediments we found Proteobacteria, Chlorobi, Actinobacteria, Planctomycetes, and Armatimonadetes as dominating phyla. It is noteworthy that differences in sampling strategies between the benthic microbial mat samples (carefully collected by a scuba diver) and deep lake sediments (Ekman dredge) hampered this comparison. Based on in situ images in the oxic basin (Figure 2D), we would have expected that Cyanobacteria were more abundant.

Further, Proteobacteria were the most or second most abundant phylum in all lake samples (benthic, pelagic, ice). Together with Bacteroidetes and Actinobacteria, they comprised 99.2\% of the bacteriome in Lake Untersee sediments. Koo et al. (2017b) found that the amount of Cyanobacteria in three distinct laminae of a benthic microbial mat from Lake Untersee decreased with depth ranging from about $90 \%$ (top) to $20 \%$ (bottom). In our study, only bulk samples were processed and hence, results are not directly comparable. However, the relative abundance of Cyanobacteria within benthic microbial mats in both studies was in the same range.

Cyanobacteria are the most important phototrophs in freshwater and terrestrial ecosystems (Vincent, 2000; Namsaraev et al., 2010; Chrismas et al., 2015) and colonize many habitats in Antarctica (Makhalanyane et al., 2015). The scarcity of vascular plants in continental Antarctica emphasizes the role of these microbial ecosystem engineers. Cyanobacteria accounted for $13 \%$ of the entire Lake Untersee Oasis bacteriome and the genera Leptolyngbya and Tychonema were present in all habitats. Generally, the highest abundances of Cyanobacteria were found in habitats associated with sediments in combination with high water availability such as cryoconite holes and benthic microbial mats, opposed to bioaerosols, ice and dry soils. Further, the same pattern occurred at RSV level, indicating a link between ribosomal sequence variants and habitat specific conditions (Tikhonov et al., 2014). For example, one Tychonema affiliated RSV was abundant only in these sediment-associated zones. The opposite pattern was observed in another RSV from the same genus. Moreover, 22 RSVs of the genus Leptolyngbya differed in their abundance within single habitats. For example, both benthic microbial mats harbored one specific Leptolyngbya related RSV that was also found in cryoconite hole 12 but the cryoconite sample contained two additional and abundant Leptolyngbya affiliated RSVs that were absent in the benthic microbial mats (Figure 8). This micro-heterogeneity within single genera may suggest that microbial communities adapt to habitat-specific conditions and merits deeper insight.

Archaea were not present in all samples. All identified RSVs belonged to the phylum Euryarchaeota and most of the counts originated from the oxic (55.77\%) and anoxic sediments (33.11\%), mainly belonging to the class Methanomicrobia. 
In contrast, the first discovery of archaea in Antarctic cryoconite holes was mainly linked with Thaumarchaeota (Cameron et al., 2012). In benthic microbial mats of Lake Untersee, Halobacteria and Methanobacteria were dominant. Their presence was also reported from the moat region of Lake Fryxell (Brambilla et al., 2001) and Halobacteria were also detected in the hypersaline Antarctic Deep Lake in the Vestfold Hills (Bowman et al., 2000).

Archaeal RSVs in cryoconite holes accounted for $9.42 \%$ of all amplicon counts and were primarily affiliated with Euryarchaeota. Abundant RSVs belonging to Methanomicrobia were also present in lake sediments, suggesting that the glacier could be a biotic source for Lake Untersee not only for bacteria but also for archaea.

\section{Consequences of Climatic Changes in the Untersee Oasis}

By the end of this century, ice-free regions in Antarctica could increase by $25 \%$ (Lee et al., 2017). Newly exposed rocks and soils will decrease the overall reflectance and hence absorb more solar energy resulting in higher melt rates supporting microbial life in cold and oligotrophic environments. Considering the climatic history that led to the present setting of Lake Untersee and the Anuchin Glacier (Schwab, 1998), the rate of increase in glacier retreat may be considered as a fast one (Figure 3). The average temperature during the austral summer fieldwork season 2015 already approximated $0^{\circ} \mathrm{C}$. Further, daily temperature maxima spiked above the freezing point which was also evident in the long-term meteorological dataset (Andersen et al., 2015) and in 1996, a rain event was witnessed (Schwab, 1998).

Estimates show that rising temperatures will lead to substantial changes only within a few decades. As a consequence, moat regions [as observed in perennially ice-covered lakes of the McMurdo Dry Valleys, e.g., Lake Fryxell (Brambilla et al., 2001; Hall et al., 2017)] would enhance the rate of biotic input from supraglacial habitats into the lake, enable atmospheric exchanges and the $\mathrm{pH}$ of the waterbody would be reduced by the introduction of dissolved $\mathrm{CO}_{2}$ because of the formation of meltwater channels on the glacier (Andersen et al., 2015). These chemical and physical changes would most likely affect microbial communities of the Oasis. Further, satellite-based surface temperature data (Supplementary Figure 5) already indicate that the Anuchin Glacier and the ice cover of Lake Untersee are warmer compared to ice surfaces adjacent to the Oasis. This warming effect may be explained by katabatic winds as described in other areas of Antarctica (Lenaerts et al., 2016) and require further investigation in context with water availability for microbial life.

\section{CONCLUSION}

The Anuchin Glacier harbors bacterial and archaeal communities in cryoconite holes and surface glacier ice. Based on the observed species and the Shannon index, we showed that both supraglacial habitats are significantly different from each other with respect to their microbial community. On average, cryoconite holes covered only $3.46 \%$ of the Anuchin glacier and hence we inferred that the volumetric fraction of cryoconite holes to the annual glacial melt volume was low. In this context, we consider the proportion of cryoconite biota as source for benthic microbial mats within Lake Untersee as substantial while the fraction of supraglacial ice was a neglectable biotic source for the microbiome of Lake Untersee. This finding is rather surprising considering the masses of ice that eventually drain into the lake and emphasizes the potential role of still unexplored englacial and subglacial zones.

Regarding this source tracking analysis, pandora's box about which habitat is the source and which the sink is extremely tricky to open. As it has been shown in other studies that microbes traveling in the air are still viable and are hence biotic inoculators of other habitats microbial settlement is in a constant loop. It is not simply a downstream inoculation but might be recycled repeatedly. However, the main vector might still be deriving from cryoconite environments which may act as a determining factor for the microbiota in the lake.

Despite the presence of the thick ice cover of Lake Untersee which slows down shuttling of matter into the lake, cryoconite holes can be considered as biotic inoculation vectors that enable an indirect transfer of biota from soils and aerosols to the lake.

Here, cryoconite holes shared more genera with supraglacial ice $(74.7 \%)$ than with aerosols and soils combined (53\%) and therefore we reject our initial hypothesis that cryoconite hole microbial communities were dominated by microbial assemblages found in aerosols and adjacent soils. Further, from 150 genera in cryoconite holes, $69.3 \%$ of them were also present within Lake Untersee (including the lake ice cover). Considering this finding in combination with the source tracking analysis, we accept our hypothesis (b) that cryoconite hole microbial communities are mirrored in Lake Untersee environments.

The combination of wind driven temperature changes and global rising temperatures makes the Lake Untersee Oasis prone to rapid changes compared to other Antarctic regions. Rising temperatures will increase the availability of liquid water and hence induce glacio-morphological changes, reshaping habitats and will possibly alter the microbiome of the oasis. These changes require thorough monitoring to fully understand potential shifts in the microbiome. For this purpose, the present study has provided a reference database for future studies in context with climate change at Lake Untersee Oasis.

\section{AUTHOR CONTRIBUTIONS}

KW designed the study and collected samples (except benthic microbial mat samples that were collected by DA) during the Antarctic expedition 2015 that was led by DA. KW, and AP extracted DNA and did all subsequent genome analyses. KW and BS wrote most of the manuscript that was reviewed by all authors. Statistical analyses were done by AP.

\section{FUNDING}

This study was supported by the Tawani Foundation of Chicago, the Trottier Family Foundation, NASA's Exobiology 
and Astrobiology Programs, and the Arctic and Antarctic Research Institute.

\section{ACKNOWLEDGMENTS}

The Antarctic Logistics Centre International (ALCI, Cape Town, South Africa) and the Von Braun Center for Science Innovation provided logistical support. We are especially thankful to Colonel (IL) J. N. Pritzker, IL ARNG (retired),

\section{REFERENCES}

Amato, P., Joly, M., Besaury, L., Oudart, A., Taib, N., Moné, A. I., et al. (2017). Active microorganisms thrive among extremely diverse communities in cloud water. PLoS One 12:e0182869. doi: 10.1371/journal.pone. 0182869

Andersen, D. T., McKay, C. P., and Lagun, V. (2015). Climate conditions at perennially ice-covered Lake Untersee, East Antarctica. J. Appl. Meteorol. Climatol. 54, 1393-1412. doi: 10.1175/jamc-d-14-0251.1

Andersen, D. T., Sumner, D. Y., Hawes, I., Webster-Brown, J., and Mckay, C. P. (2011). Discovery of large conical stromatolites in Lake Untersee. Antarctica. Geobiology 9, 280-293. doi: 10.1111/j.1472-4669.2011.00279.x

Anesio, A. M., and Laybourn-Parry, J. (2012). Glaciers and ice sheets as a biome. Trends Ecol. Evol. 27, 219-225. doi: 10.1016/j.tree.2011.09.012

Bagshaw, E. A., Tranter, M., Wadham, J. L., Fountain, A. G., Dubnick, A., and Fitzsimons, S. (2016). Processes controlling carbon cycling in Antarctic glacier surface ecosystems. Geochem. Persp. Lett. 2, 44-54. doi: 10.7185/geochemlet. 1605

Boetius, A., Anesio, A. M., Deming, J. W., Mikucki, J. A., and Rapp, J. Z. (2015). Microbial ecology of cryosphere: sea ice and glacial habitats. Nat. Rev. Microbiol. 13:677. doi: 10.1038/nrmicro3522

Bottos, E. M., Woo, A. C., Zawar-Reza, P., Pointing, S. B., and Cary, S. C. (2014). Airborne bacterial populations above desert soils of the McMurdo Dry Valleys. Antarctica. Microb. Ecol. 67, 120-128. doi: 10.1007/s00248-013-0296-y

Bowman, J. P., McCammon, S. A., Rea, S. M., and McMeekin, T. A. (2000). The microbial composition of three limnologically disparate hypersaline Antarctic lakes. FEMS Microbiol. Lett. 183, 81-88. doi: 10.1111/j.1574-6968.2000. tb08937.x

Bowman, J. S., and Deming, J. W. (2017). Wind-driven distribution of bacteria in coastal Antarctica: evidence from the Ross Sea region. Polar Biol. 40, 25-35. doi: 10.1007/s00300-016-1921-2

Boyd, W. L., Staley, J. T., and Boyd, J. W. (2013). "Ecology of soil microorganisms of Antarctica," in Antarctic Soils and Soil Forming Processes, ed. J. C. Tedrow (Washington, D.C: American Geophysical Union).

Brambilla, E., Hippe, H., Hagelstein, A., Tindall, B. J., and Stackebrandt, E. (2001). $16 \mathrm{~S}$ rDNA diversity of cultured and uncultured prokaryotes of a mat sample from Lake Fryxell, McMurdo Dry Valleys, Antarctica. Extremophiles 5, 23-33. doi: $10.1007 /$ s007920000169

Burton-Johnson, A., Black, M., Fretwell, P. T., and Kaluza-Gilbert, J. (2016). An automated methodology for differentiating rock from snow, clouds and sea in Antarctica from Landsat 8 imagery: a new rock outcrop map and area estimation for the entire Antarctic continent. Cryosphere 10, 1665-1677. doi: 10.5194/tc-10-1665-2016

Callahan, B. J., McMurdie, P. J., Rosen, M. J., Han, A. W., Johnson, A. J. A., and Holmes, S. P. (2016). DADA2: High-resolution sample inference from Illumina amplicon data. Nat. Methods 13:581. doi: 10.1038/nmeth.3869

Cameron, K. A., Hodson, A. J., and Osborn, A. M. (2012). Structure and diversity of bacterial, eukaryotic and archaeal communities in glacial cryoconite holes from the Arctic and the Antarctic. FEMS Microbiol. Ecol. 82, 254-267. doi: 10.1111/j.1574-6941.2011.01277.x

Cameron, K. A., Stibal, M., Zarsky, J. D., Gözdereliler, E., Schostag, M., and Jacobsen, C. S. (2016). Supraglacial bacterial community structures vary across the Greenland ice sheet. FEMS Microbiol. Ecol. 92:fiv164. doi: 10.1093/femsec/ fiv164 of the Tawani Foundation. We are grateful for valuable comments from Asim Bej, Chris Bellas and the reviewers who improved the manuscript.

\section{SUPPLEMENTARY MATERIAL}

The Supplementary Material for this article can be found online at: https://www.frontiersin.org/articles/10.3389/fmicb. 2019.01019/full\#supplementary-material

Caporaso, J. G., Lauber, C. L., Walters, W. A., Berg-Lyons, D., Huntley, J., Fierer, N., et al. (2012). Ultra-high-throughput microbial community analysis on the Illumina HiSeq and MiSeq platforms. ISME J. 6:1621. doi: 10.1038/ismej. 2012.8

Cary, S. C., McDonald, I. R., Barrett, J. E., and Cowan, D. A. (2010). On the rocks: the microbiology of Antarctic Dry Valley soils. Nat. Rev. Microbiol. 8:129. doi: 10.1038/nrmicro2281

Chrismas, N. A. M., Anesio, A. M., and Sánchez-Baracaldo, P. (2015). Multiple adaptations to polar and alpine environments within cyanobacteria: a phylogenomic and Bayesian approach. Front. Microbiol. 6:1070. doi: 10.3389/ fmicb.2015.01070

Christner, B. C., Kvitko, B. H., and Reeve, J. N. (2003). Molecular identification of bacteria and eukarya inhabiting an Antarctic cryoconite hole. Extremophiles 7, 177-183. doi: 10.1007/s00792-002-0309-0

Christner, B. C., Mikucki, J. A., Foreman, C. M., Denson, J., and Priscu, J. C. (2005). Glacial ice cores: a model system for developing extraterrestrial decontamination protocols. Icarus 174, 572-584. doi: 10.1016/j.icarus.2004. 10.027

Cook, J., Edwards, A., Takeuchi, N., and Irvine-Fynn, T. (2016). Cryoconite: the dark biological secret of cryosphere. Prog. Phys. Geogr. 40, 66-111. doi: 10.1177/ 0309133315616574

Crawford, I., Gallagher, M. W., Bower, K. N., Choularton, T. W., Flynn, M. J., Ruske, S., et al. (2017). Real-time detection of airborne fluorescent bioparticles in Antarctica. Atmos. Chem. Phys. 17, 14291-14307. doi: 10.5194/acp-1714291-2017

Cuthbertson, L., and Pearce, D. A. (2017). “Aeromicrobiology,” in Psychrophiles: From Biodiversity to Biotechnology, ed. R. Margesin (Cham: Springer International Publishing), 41-55. doi: 10.1007/978-3-319-57057-0_3

Diaz, M. A., Adams, B. J., Welch, K. A., Welch, S. A., Opiyo, S. O., Khan, A. L., et al. (2018). Aeolian material transport and its role in landscape connectivity in the McMurdo Dry Valleys, Antarctica. J. Geophys. Res. Earth Surf. 123, 3323-3337. doi: 10.1029/2017JF004589

Doyle, S. M., Montross, S. N., Skidmore, M. L., and Christner, B. C. (2013). Characterizing microbial diversity and the potential for metabolic function at $-15{ }^{\circ} \mathrm{C}$ in the basal ice of Taylor Glacier, Antarctica. Biology 2, 1034-1053. doi: 10.3390/biology2031034

Edwards, A., and Cameron, K. A. (2017). "Microbial life in supraglacial environments," in Psychrophiles: From Biodiversity to Biotechnology, ed. R. Margesin (Cham: Springer International Publishing), 57-81. doi: 10.1007/9783-319-57057-0_4

Edwards, A., Pachebat, J. A., Swain, M., Hegarty, M., Hodson, A. J., Irvine-Fynn, T. D., et al. (2013a). A metagenomic snapshot of taxonomic and functional diversity in an alpine glacier cryoconite ecosystem. Environ. Res. Lett. 8:035003. doi: 10.1088/1748-9326/8/3/035003

Edwards, A., Rassner, S. M. E., Anesio, A. M., Worgan, H. J., Irvine-Fynn, T. D. L., Wyn Williams, H., et al. (2013b). Contrasts between the cryoconite and icemarginal bacterial communities of Svalbard glaciers. Polar. Res. 32:19468. doi: 10.3402/polar.v32i0.19468

Fierer, N., Liu, Z., Rodríguez-Hernández, M., Knight, R., Henn, M., and Hernandez, M. T. (2008). Short-term temporal variability in airborne bacterial and fungal populations. J. Appl. Environ. Microbiol. 74, 200-207. doi: 10.1128/ aem.01467-07

Filippova, S. N., Surgucheva, N. A., Kulikov, E. E., Sorokin, V. V., Akimov, V. N., Bej, A. K., et al. (2013). Detection of phage infection in the bacterial 
population of Lake Untersee (Antarctica). Microbiology 82, 383-386. doi: 10. 1134/S0026261713030041

Findlay, R. H., and Battin, T. J. (2016). "The microbial ecology of benthic environments," in Manual of Environmental Microbiology, 4th Edn, eds M. Yates, C. Nakatsu, R. Miller, and S. Pillai (Washington, DC: ASM Press).

Fomenkov, A., Akimov, V. N., Vasilyeva, L. V., Andersen, D. T., Vincze, T., and Roberts, R. J. (2017). Complete genome and methylome analysis of psychrotrophic bacterial isolates from Lake Untersee in Antarctica. Genome Announc. 5:e1753-16. doi: 10.1128/genomeA.01753-16

Fountain, A. G., Tranter, M., Nylen, T. H., Lewis, K. J., and Mueller, D. R. (2004). Evolution of cryoconite holes and their contribution to meltwater runoff from glaciers in the McMurdo Dry Valleys, Antarctica. J. Glaciol. 50, 35-45. doi: $10.3189 / 172756504781830312$

Franzetti, A., Navarra, F., Tagliaferri, I., Gandolfi, I., Bestetti, G., Minora, U., et al. (2017). Potential sources of bacteria colonizing the cryoconite of an Alpine glacier. PLoS One 12:e0174786. doi: 10.1371/journal.pone.0174786

Haendel, D., Hermichen, W. D., Höfling, R., and Kowski, P. (2011). Hydrology of the lakes in Central Wohlthat Massif, East Antarctica: new results. Isotopes Environ. Health Stud. 47, 402-406. doi: 10.1080/10256016.2011.630464

Hall, C. M., Castro, M. C., Kenig, F., and Doran, P. T. (2017). Constraining the recent history of the perennially ice-covered Lake Bonney, East Antarctica using $\mathrm{He}, \mathrm{Kr}$ and Xe concentrations. Geochim. Cosmochim. Acta 209, 233-253. doi: 10.1016/j.gca.2017.04.023

Heberle, H., Meirelles, G. V., da Silva, F. R., Telles, G. P., and Minghim, R. (2015). InteractiVenn: a web-based tool for the analysis of sets through Venn diagrams. BMC Bioinform. 16:169. doi: 10.1186/s12859-015-0611-3

Hermichen, W. D., Kowski, P., and Wand, U. (1985). Lake Untersee, a first isotope study of the largest freshwater lake in the interior of East Antarctica. Nature 315:131. doi: 10.1038/315131a0

Hiller, A., Wand, U., Kämpf, H., and Stackebrandt, W. (1988). Occupation of the Antarctic continent by petrels during the past 35000 years: inferences from a 14C study of stomach oil deposits. Polar Biol. 9, 69-77. doi: 10.1007/bf00442032

Hodson, A., Paterson, H., Westwood, K., Cameron, K., and Laybourn-Parry, J. (2013). A blue-ice ecosystem on the margins of the East Antarctic ice sheet. J. Glaciol. 59, 255-268. doi: 10.3189/2013JoG12J052

Hotaling, S., Hood, E., and Hamilton, T. L. (2017). Microbial ecology of mountain glacier ecosystems: biodiversity, ecological connections and implications of a warming climate. Environ. Microbiol. 19, 2935-2948. doi: 10.1111/1462-2920. 13766

Howat, I., Morin, P., Porter, C., and Noh, M. J. (2018). The Reference Elevation Model of Antarctica. Washington, DC: Harvard Dataverse.

Huang, J. P., Swain, A. K., Andersen, D. T., and Bej, A. K. (2014). Bacterial diversity within five unexplored freshwater lakes interconnected by surface channels in East Antarctic Dronning Maud Land (Schirmacher Oasis) using amplicon pyrosequencing. Polar. Biol. 37, 359-366. doi: 10.1007/s00300-013-1436-z

Huang, J. P., Swain, A. K., Thacker, R. W., Ravindra, R., Andersen, D. T., and Bej, A. K. (2013). Bacterial diversity of the rock-water interface in an East Antarctic freshwater ecosystem, Lake Tawani(P). Aquat. Biosyst. 9:4. doi: 10.1186/20469063-9-4

Klindworth, A., Pruesse, E., Schweer, T., Peplies, J., Quast, C., Horn, M., et al. (2013). Evaluation of general 16S ribosomal RNA gene PCR primers for classical and next-generation sequencing-based diversity studies. Nucleic Acids Res. 41:e1. doi: 10.1093/nar/gks808

Klymiuk, I., Bambach, I., Patra, V., Trajanoski, S., and Wolf, P. (2016). 16S based microbiome analysis from healthy subjects' skin swabs stored for different storage periods reveal phylum to genus level changes. Front. Microbiol. 7:2012. doi: $10.3389 /$ fmicb.2016.02012

Knights, D., Kuczynski, J., Charlson, E. S., Zaneveld, J., Mozer, M. C., Collman, R. G., et al. (2011). Bayesian community-wide culture-independent microbial source tracking. Nat. Methods 8:761. doi: 10.1038/nmeth.1650

Koo, H., Hakim, J. A., Morrow, C. D., Eipers, P. G., Davila, A., Andersen, D. T., et al. (2017a). Comparison of two bioinformatics tools used to characterize the microbial diversity and predictive functional attributes of microbial mats from Lake Obersee, Antarctica. J. Microbiol. Methods 140, 15-22. doi: 10.1016/ j.mimet.2017.06.017

Koo, H., Mojib, N., Hakim, J. A., Hawes, I., Tanabe, Y., Andersen, D. T., et al. (2017b). Microbial communities and their predicted metabolic functions in growth laminae of a unique large conical mat from Lake Untersee, East Antarctica. Front. Microbiol. 8:1347. doi: 10.3389/fmicb.2017.01347

Koskinen, K., Pausan, M. R., Perras, A. K., Beck, M., Bang, C., Mora, M., et al. (2017). First insights into the diverse human archaeome: specific detection of Archaea in the gastrointestinal tract, lung, and nose and on skin. mBio 8:e824-817. doi: 10.1128/mBio.00824-817

Lee, J. R., Raymond, B., Bracegirdle, T. J., Chadès, I., Fuller, R. A., Shaw, J. D., et al. (2017). Climate change drives expansion of Antarctic ice-free habitat. Nature 547:49. doi: 10.1038/nature22996

Legrand, M., and Mayewski, P. (1997). Glaciochemistry of polar ice cores: a review. Rev. Geophys. 35, 219-243. doi: 10.1029/96RG03527

Lenaerts, J. T. M., Lhermitte, S., Drews, R., Ligtenberg, S. R. M., Berger, S., Helm, V., et al. (2016). Meltwater produced by wind-albedo interaction stored in an East Antarctic ice shelf. Nat. Clim. Change 7:58. doi: 10.1038/nclimate3180

Mackey, T. J., Sumner, D. Y., Hawes, I., Jungblut, A. D., and Andersen, D. T. (2015). Growth of modern branched columnar stromatolites in Lake Joyce, Antarctica. Geobiology 13, 373-390. doi: 10.1111/gbi.12138

Makhalanyane, T. P., Valverde, A., Velázquez, D., Gunnigle, E., Van Goethem, M. W., Quesada, A., et al. (2015). Ecology and biogeochemistry of cyanobacteria in soils, permafrost, aquatic and cryptic polar habitats. Biodivers. Conserv. 24, 819-840. doi: 10.1007/s10531-015-0902-Z

McMurdie, P. J., and Holmes, S. (2013). Phyloseq: an R package for reproducible interactive analysis and graphics of microbiome census data. PLoS One 8:e61217. doi: 10.1371/journal.pone.0061217

McMurdie, P. J., and Holmes, S. (2014). Waste not, want not: why rarefying microbiome data is inadmissible. PLoS Comput. Biol. 10:e1003531. doi: 10.1371/ journal.pcbi.1003531

Michaud, A. B., Šabacká, M., and Priscu, J. C. (2012). Cyanobacterial diversity across landscape units in a polar desert: Taylor Valley, Antarctica. FEMS Microbiol. Ecol. 82, 268-278. doi: 10.1111/j.1574-6941.2012.01297.x

Moorhead, D. L., Barrett, J. E., Virginia, R. A., Wall, D. H., and Porazinska, D. (2003). Organic matter and soil biota of upland wetlands in Taylor Valley, Antarctica. Polar Biol. 26, 567-576. doi: 10.1007/s00300-003-0524-x

Mora, M., Perras, A., Alekhova, T. A., Wink, L., Krause, R., Aleksandrova, A., et al. (2016). Resilient microorganisms in dust samples of the international space station-survival of the adaptation specialists. Microbiome 4:65. doi: 10.1186/ s40168-016-0217-7

Namsaraev, Z., Mano, M., Fernandez, R., and Wilmotte, A. (2010). Biogeography of terrestrial cyanobacteria from Antarctic ice-free areas. Ann. Glaciol. 51, 171-177. doi: 10.3189/172756411795931930

Obbels, D., Verleyen, E., Mano, M. J., Namsaraev, Z., Sweetlove, M., Tytgat, B., et al. (2016). Bacterial and eukaryotic biodiversity patterns in terrestrial and aquatic habitats in the Sør Rondane Mountains, Dronning Maud Land, East Antarctica. FEMS Microbiol. Ecol. 92:fiw041. doi: 10.1093/femsec/fiw041

Parker, B. C., Simmons, G. M., Wharton, R. A., Seaburg, K. G., and Love, F. G. (1982). Removal of organic and inorganic matter from Antarctic lakes by aerial escape of bluegreen algal mats. J. Phycol. 18, 72-78. doi: 10.1111/j.1529-8817. 1982.tb03158.x

Pikuta, E. V., Lyu, Z., Hoover, R. B., Liu, Y., Patel, N. B., Busse, H. J., et al. (2017). Williamwhitmania taraxaci gen. nov., sp. nov., a proteolytic anaerobe with a novel type of cytology from Lake Untersee in Antarctica, description of Williamwhitmaniaceae fam. nov., and emendation of the order Bacteroidales Krieg 2012. Int. J. Syst. Evol. Microbiol. 67, 4132-4145. doi: 10.1099/ijsem.0. 002266

Porazinska, D. L., Fountain, A. G., Nylen, T. H., Tranter, M., Virginia, R. A., and Wall, D. H. (2004). The biodiversity and biogeochemistry of cryoconite holes from McMurdo Dry Valley Glaciers, Antarctica. Arct. Antarct. Alp. Res. 36, 84-91. doi: 10.1657/1523-0430(2004)036[0084:tbaboc]2.0.co;2

Price, P. B. (2007). Microbial life in glacial ice and implications for a cold origin of life. FEMS Microbiol. Ecol. 59, 217-231. doi: 10.1111/j.1574-6941.2006. 00234.x

Priscu, J. C., Fritsen, C. H., Adams, E. E., Giovannoni, S. J., Paerl, H. W., McKay, C. P., et al. (1998). Perennial Antarctic lake ice: an oasis for life in a polar desert. Science 280, 2095-2098. doi: 10.1126/science.280.5372.2095

Priscu, J. C., Wolf, C. F., Takacs, C. D., Fritsen, C. H., Laybourn-Parry, J., Roberts, E. C., et al. (1999). Carbon transformations in a perennially ice-covered Antarctic lake. BioScience 49, 997-1008. doi: 10.1525/bisi.1999.49.12.997 
Quast, C., Pruesse, E., Yilmaz, P., Gerken, J., Schweer, T., Yarza, P., et al. (2013). The SILVA ribosomal RNA gene database project: improved data processing and web-based tools. Nucleic Acids Res. 41, 590-596. doi: 10.1093/nar/gks1219

Rignot, E., Mouginot, J., Morlighem, M., Seroussi, H., and Scheuchl, B. (2014). Widespread, rapid grounding line retreat of Pine Island, Thwaites, Smith, and Kohler glaciers, West Antarctica, from 1992 to 2011. Geophys. Res. Lett. 41, 3502-3509. doi: 10.1002/2014GL060140

Šabacká, M., Priscu, J. C., Basagic, H. J., Fountain, A. G., Wall, D. H., Virginia, R. A., et al. (2012). Aeolian flux of biotic and abiotic material in Taylor Valley, Antarctica. Geomorphology 15, 102-111. doi: 10.1016/j.geomorph.2011. 12.009

Sattler, B., Puxbaum, H., and Psenner, R. (2001). Bacterial growth in supercooled cloud droplets. Geophys. Res. Lett. 28, 239-242. doi: 10.1029/2000GL011684

Schindelin, J., Arganda-Carreras, I., Frise, E., Kaynig, V., Longair, M., Pietzsch, T., et al. (2012). Fiji: an open-source platform for biological-image analysis. Nat. Methods 9:676. doi: 10.1038/nmeth.2019

Schwab, M. (1998). Reconstruction of the late quaternary climatic and environmental history of the Schirmacher Oasis and the Wohlthat Massif (East Antarctica). Rep. Polar Res. 293:128. doi: 10.1016/j.quaint.2010.11.025

Simonov, I., Stackebrandt, W., Haendel, D., Kaup, E., Kämpf, H., and Loopmann, A. (1985). Komplexe naturwissenschaftliche untersuchungen am unter- und obersee, zentrales dronning-maud-land, Antarktika. Petermanns Geogr. Mitt. 129, 125-135.

Steel, H. C. B., McKay, C. P., and Andersen, D. T. (2015). Modeling circulation and seasonal fluctuations in perennially ice-covered and ice-walled Lake Untersee, Antarctica. Limnol. Oceanogr. 60, 1139-1155. doi: 10.1002/lno.10086

Takeuchi, N., Kohshima, S., and Seko, K. (2001). Structure, formation, and darkening process of albedo-reducing material (Cryoconite) on a Himalayan glacier: a granular algal mat growing on the glacier. Arct. Antarct. Alp. Res. 33, 115-122. doi: 10.1080/15230430.2001.12003413

Tanabe, Y., Yasui, S., Osono, T., Uchida, M., Kudoh, S., and Yamamuro, M. (2017). Abundant deposits of nutrients inside lakebeds of Antarctic oligotrophic lakes. Polar Biol. 40, 603-613. doi: 10.1007/s00300-016-1983-1
Tikhonov, M., Leach, R. W., and Wingreen, N. S. (2014). Interpreting 16S metagenomic data without clustering to achieve sub-OTU resolution. ISME J. 9:68. doi: 10.1038/ismej.2014.117

Vincent, W. F. (2000). "Cyanobacterial dominance in the polar regions," in The Ecology of Cyanobacteria, Vol. 12, eds B. A. Whitton and M. Potts (Dordrecht: Kluwer Academic Publishers), 321-340. doi: 10.1007/0-306-46855-7_12

Wand, U., and Perlt, J. (1999). Glacial boulders 'floating' on the ice cover of Lake Untersee, East Antarctica. Antarct. Sci. 11, 256-260. doi: 10.1017/ S0954102099000310

Wand, U., Samarkin, V. A., Nitzsche, H. M., and Hubberten, H. W. (2006). Biogeochemistry of methane in the permanently ice-covered Lake Untersee, central Dronning Maud Land, East Antarctica. Limnol. Oceanogr. 51, 11801194. doi: 10.4319/lo.2006.51.2.1180

Wand, U., Schwarz, G., Brüggemann, E., and Bräuer, K. (1997). Evidence for physical and chemical stratification in Lake Untersee (central dronning Maud Land, East Antarctica). Antarct. Sci. 9, 43-45. doi: 10.1017/s0954102097000060

Wharton, R. A., McKay, C. P., Simmons, G. M., and Parker, B. C. (1985). Cryoconite holes on glaciers. Bioscience 35, 499-503. doi: 10.2307/1309818

Wilkins, D., Yau, S., Williams, T. J., Allen, M. A., Brown, M. V., DeMaere, M. Z., et al. (2013). Key microbial drivers in Antarctic aquatic environments. FEMS Microbiol. Rev. 37, 303-335. doi: 10.1111/1574-6976.12007

Conflict of Interest Statement: The authors declare that the research was conducted in the absence of any commercial or financial relationships that could be construed as a potential conflict of interest.

Copyright (c) 2019 Weisleitner, Perras, Moissl-Eichinger, Andersen and Sattler. This is an open-access article distributed under the terms of the Creative Commons Attribution License (CC BY). The use, distribution or reproduction in other forums is permitted, provided the original author(s) and the copyright owner(s) are credited and that the original publication in this journal is cited, in accordance with accepted academic practice. No use, distribution or reproduction is permitted which does not comply with these terms. 